\title{
Fibre-Cement Panel Ventilated Façade Smart Control System
}

\author{
Anna Adamczak-Bugno *(D), Grzegorz Świt and Aleksandra Krampikowska (D) \\ Faculty of Civil Engineering and Architecture, Kielce University of Technology, 25-314 Kielce, Poland; \\ gswit@tu.kielce.pl (G.Ś.); a kramp@tu.kielce.pl (A.K.) \\ * Correspondence: aadamczak@tu.kielce.pl
}

Citation: Adamczak-Bugno, A.; Świt G.; Krampikowska, A. Fibre-Cement Panel Ventilated Façade Smart Control System. Materials 2021, 14, 5076. https://doi.org/10.3390/ ma14175076

Academic Editor: Edyta Pawluczuk

Received: 15 August 2021

Accepted: 2 September 2021

Published: 5 September 2021

Publisher's Note: MDPI stays neutral with regard to jurisdictional claims in published maps and institutional affiliations.

Copyright: (c) 2021 by the authors. Licensee MDPI, Basel, Switzerland. This article is an open access article distributed under the terms and conditions of the Creative Commons Attribution (CC BY) license (https:/ / creativecommons.org/licenses/by/ $4.0 /)$.

\begin{abstract}
This paper outlines a design for a fibre-cement panel ventilated façade smart control system based on the acoustic emission method. The paper also provides methodology and test results, as well as statistical analysis of the three-point bending results with AE signal acquisition as a basis for the development of the system in question. The test items were samples cut from a full-size fibre-cement panel for interior and exterior use, according to the standard guidelines. The recorded acoustic emission signals were classified statistically into four classes, which were assigned to the processes occurring in the material structure as a result of the applied load. The system development was based on the differences between the characteristics of the individual signal classes and their number for each test case, as well as on the different distribution of successive classes over time. Given the results of the tests and the resulting conclusions indicating the applicability of the acoustic emission method (based on signal classification using the k-means algorithm for the assessment of variations in the mechanical parameters of cement-fibre composites), a methodology for such assessment was therefore developed. The approach proposed is a reasonable method for assessing the variation in mechanical parameters of fibre-cement panels on the basis of the parameters determined by the non-destructive method indicated.
\end{abstract}

Keywords: ventilated façade; acoustic emission method; fibre-cement boards

\section{Introduction}

Fibre-reinforced cement-based products have been used in the construction industry for over a century. The inventor of the first fibre-cement panels was an engineer from the Czech Republic, Ludwik Hatschek [1-4], who led the development and patenting of the technology to produce this type of composite. The original product, called 'Eternit', demonstrated high strength and durability while being light, moisture-resistant, and non-combustible. The combination of these parameters in fibre-cement panels was an outstanding innovation globally. The fibre-cement panels have proven to be the most popular roofing material in the world over the last century [5]. The backlash came when one component, asbestos, was found to be carcinogenic [6]. In the 1990s, work began on replacing the toxic component. Since then, the cement matrix has been reinforced with fibres that do not pose a health risk to users, mainly cellulose fibres. Fibre-cement panels available on the market today may include cement, cellulose fibres, synthetic fibres, and various additives and admixtures [7] which makes them a different type of building product in relation to the original. Limestone dust, mica, perlite, kaolin, and microspheres are the most common additives and fillers in fibre-cement panels [8-12]. Products containing recycled materials (cellulose recycling) are also available [13]. All types of fillers used contribute to the innovative properties of fibre-cement products and are part of sustainable development.

The cement-fibre panels are a material exposed to defects and damage, both during the manufacturing process and in service. This fact significantly affects their properties and durability parameters. The production of panels is a complex process governed by the properties and quantities of the individual components and how they are incorporated into the finished product [14-18]. During the consecutive production stages, the panels 
are exposed to defects and damage in the form of large pores, delamination, cracks and discontinuities in the reinforcement fibre distribution. In service conditions, the fibrecement panels are exposed to variable atmospheric and environmental conditions, both in terms of temperature and humidity, in the form of significant temperature fluctuations, including transitions through $0{ }^{\circ} \mathrm{C}$ in a daily cycle (cyclic freeze-thaw phenomenon), the likelihood of chemical aggression in the form of acid rainfall, and exposure to ultraviolet rays [19-25]. In addition, the fibre-cement cladding panels are exposed to extreme service conditions. The most destructive of these is heat and direct fire exposure in a fire scenario. Service impacts in the form of horizontal force are also potentially damaging from a strength perspective. The occurrence of the above-mentioned conditions during the service life of the panels is related to the fact that they are used as external façade cladding in the ventilated façade system, as balcony and terrace cover panels, and as wall finishes inside buildings [26].

When these factors occur, there is a high probability that the cement-fibre panel structure will change, resulting in a deterioration of the performance and durability properties [27-30]. Therefore, cladding panels should meet the requirements set out in the standards and legislation [31], taking into account the impacts indicated. Determining the extent to which fibre-cement panels are affected by service conditions is important, particularly for the external parts of buildings, as this has a direct impact on the safe use of a building. This issue seems to be particularly relevant for tall and high-rise buildings. The question of providing a proven, reliable, and durable cladding material is therefore indisputable. The mere determination of the impact of the presented conditions on the change of strength parameters of the cement-fibre panels is one of the basic conditions of safe operation. However, it is important to stress that a very significant contribution to the final product quality and durability is also attributable to testing at the product production stage [32-34].

Fibre-cement is subject to the same processes as other cement-based products. One of the most intensive is carbonatization, the intensity of which depends, among other things, on the concentration of carbon dioxide. The way the material behaves during use is also affected by its layered structure. The studies on cement-fibre materials show that in the first years of service, the reaction between the calcium phases and carbon dioxide from air and water has a positive effect on the bonding between the product layers. However, after only about five years, reactions of the carbon with hydration products result in moisture migration tracks in the material. Long-term exposure of the panels to weather ultimately leads to a reduction in the bonding between the layers and the formation of a discontinuity in the matrix. Cellulose fibres also become particularly vulnerable due to increased moisture movement in the material and freeze-thaw cycles. The gradual depolymerisation of the fibres, resulting in, among other things, a decrease in mechanical strength, is a direct effect of these interactions. It is estimated that after about 15 years of service, the strength of cement-fibre panels decreases by up to $40 \%$ [31,32].

Due to the processes taking place in the material of cement-cellulose boards and due to the operational conditions to which they are exposed, it is necessary to at least periodically monitor the buildings made with their use. This type of control should make it possible to detect a possible decrease in the mechanical parameters of the boards.

Taking into account the conclusions of the literature review, steps were taken to select a non-destructive method that would allow the control of the built-in boards. The result of the carried-out work is the system for assessing the change in mechanical parameters of fiber-cement panels, presented in the article, based on the acoustic emission method. The paper also presents the research that is the basis for the development of the final diagnostic methodology.

\section{Materials and Methods}

The tests prior to the system development to assess the change in mechanical performance of the fibre-cement panels involved three-point bending tests on samples cut from 
full-size panels together with acoustic emission (AE) signal acquisition. The bending configuration and dimensions of the test pieces were chosen based on the standard guidelines.

The test pieces were subjected to environmental conditions (soaking in water for $1 \mathrm{~h}$ and $24 \mathrm{~h}$, cyclic freeze-thaw in an air-water environment for 10 cycles, 25 cycles, 50 cycles, and 100 cycles) and extreme conditions (burning in a laboratory oven for $3 \mathrm{~h}$ at $230{ }^{\circ} \mathrm{C}$, exposure to direct fire for $2.5 \mathrm{~min}, 5.0 \mathrm{~min}, 7.5 \mathrm{~min}, 10.0 \mathrm{~min}$ ), and were also tested in air-dry condition. The acoustic emission method in the energy approach was used as the main testing method to determine the change in mechanical parameters of cement-fibre composites.

The scheme of the test stand and a photograph of one of the tested samples are shown in Figure 1. Cuboidal $300 \times 50 \times 8 \mathrm{~mm}$ samples were cut from $1.25 \times 3.10 \mathrm{~m}$ and $8 \mathrm{~mm}$ thick panels for three-point bending. Load $F$, displacement and acoustic emission signals $\mathrm{AE}$ were recorded during the tests. The distance between the support axes $\left(l_{\mathrm{s}}\right)$ was $200 \mathrm{~mm}$. A Zwick Roell testing machine was used in the tests. The constant loading speed was $0.1 \mathrm{~mm} / \mathrm{s}$.

(a)

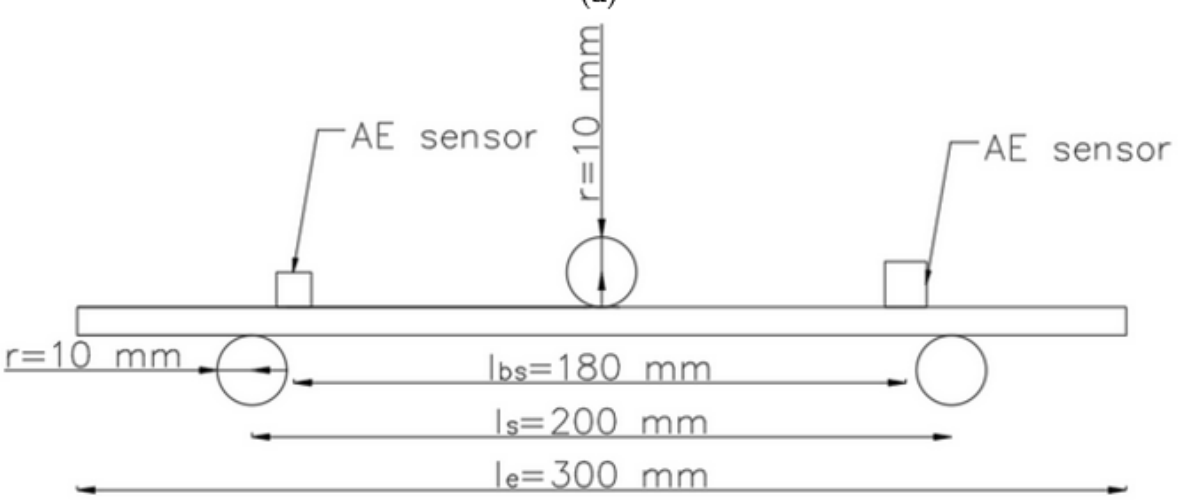

(b)

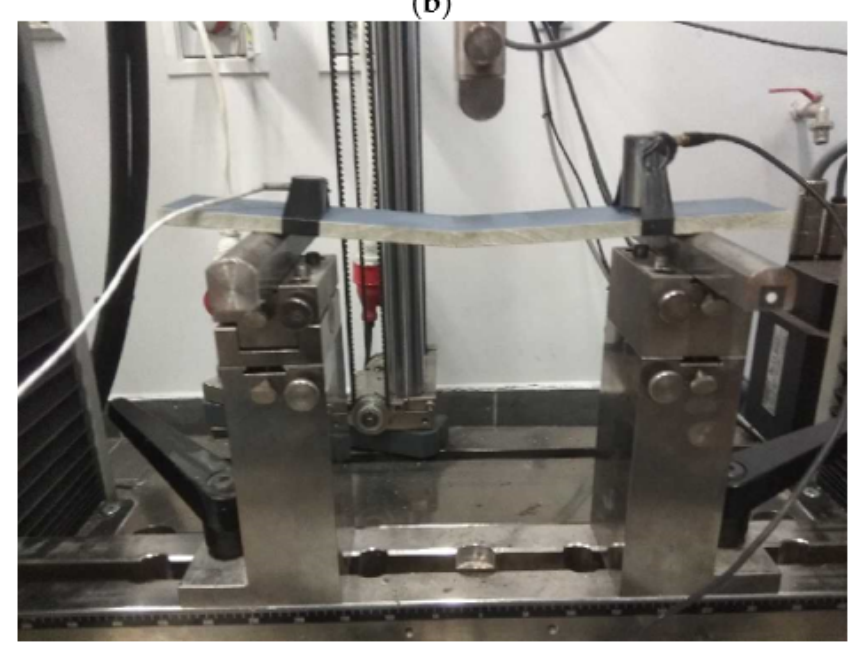

Figure 1. Test stand diagram: (a) load diagram; (b) a photograph of one of the samples.

According to the manufacturer's declaration, the boards from which the test elements were cut out consisted of Portland cement, mineral binders, cellulose fibers, color dyes, and admixtures. Accurate quantitative and qualitative data on the composition are protected by patent law. The declared technical parameters of the board are presented in Table 1.

Fourteen standard AE parameters were used to determine the change in mechanical parameters:

1. Duration;

2. Rise time;

3. Decay time; 


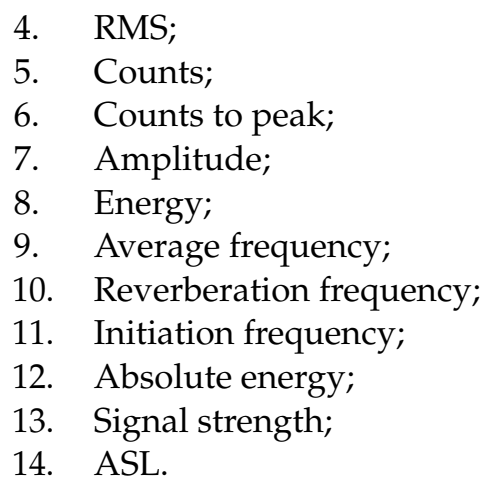

Table 1. The declared technical parameters of the boards.

\begin{tabular}{ccccc}
\hline Density & Dry state & PN-EN 12467 & $\geq 1.65$ & $\mathrm{~g} / \mathrm{cm}^{3}$ \\
$\begin{array}{c}\text { Flexural strength } \\
\text { Flexural strength }\end{array}$ & Perpendicular & PN-EN 12467 & 24.0 & $\mathrm{~N} / \mathrm{mm}^{2}$ \\
$\begin{array}{c}\text { Modulus of elasticity } \\
\text { Stretching with } \\
\text { humidity } \\
\text { Porosity }\end{array}$ & In parallel & PN-EN 12467 & 18.5 & $\mathrm{~N} / \mathrm{mm}^{2}$ \\
& & PN-EN 12467 & 12,000 & $\mathrm{~N} / \mathrm{mm}^{2}$ \\
& $0-100 \%$ & & 1.0 & $\mathrm{~mm} / \mathrm{m}$ \\
\hline
\end{tabular}

These parameters were used to classify the signals using pattern recognition methods with arbitrary class division (USPR). Scattergram of signal strength and duration were used to present the results of the tests after analysis with the created reference signal database. The advantage of creating a database of reference signals is the fact of assigning invariable characteristics to individual classes, marked by graphic symbols and colour. As a result, we can use selected parameters (preferably depicting the transformation of destructive processes) rather than all $\mathrm{AE}$ parameters to analyse the processes taking place, which facilitates the interpretation of the results by people not trained in acoustic emission testing. According to Świt et al. [33], analysis using the parameters of signal power and duration illustrates well the distribution of signals of the different classes and makes it possible to observe the differences between them.

To assess the change in mechanical parameters as affected by service (environmental and extreme) conditions, a three-point bending test was conducted during the MOR flexural strength test. The standard parameter for assessing the change (deterioration) of the mechanical parameters of the tested cement-fibre panels are the classes of acoustic emission signals with the destructive processes assigned to them, namely fibre cracking and fibre pull-out from the cement matrix. The decline in recorded events of this nature allowed assessment of the extent to which mechanical parameters change when exposed to service conditions. The other classes serve as a preliminary confirmation of the presence of other destructive processes in the tested pieces.

On the basis of the preliminary tests performed, it was confirmed that the external panels have the mechanical parameters as declared by the manufacturers. It is important to note, however, that the fibre-cement panel compositions and their technological process are strictly protected by the manufacturers, and information on specific components, their quantities and suppliers, and production details are restricted extensively. The fibre-cement panels tested were made using basic components, such as Portland cement CEM I 42.5N, cellulose fibres, synthetic fibres PVA and additives, such as limestone dust. The coloured panels have additional colouring admixtures. All panels were manufactured according to the Hatschek process.

The test samples were cut in one direction, parallel to the length of the panel, avoiding the $50 \mathrm{~mm}$ edge zone of the panel.

The changes in the mechanical parameters of the fibre-cement panels under environmental and extreme service conditions were assessed for the following test cases: 
- Air-dry condition (no destruction, reference condition, referential);

- Soaking in water for $1 \mathrm{~h}$;

- $\quad$ Soaking in water for $24 \mathrm{~h}$;

- 25 soaking-drying cycles;

- 50 bath-drying cycles;

- 10 freeze-thaw cycles;

- 25 freeze-thaw cycles;

- 50 freeze-thaw cycles;

- 100 freeze-thaw cycles;

- Direct exposure to flame (resulting in a temperature of up to $400{ }^{\circ} \mathrm{C}$ ) for $2.5 \mathrm{~min}$;

- Direct exposure to flame (resulting in a temperature of up to $400^{\circ} \mathrm{C}$ ) for $5 \mathrm{~min}$;

- Direct exposure to flame (resulting in a temperature of up to $400^{\circ} \mathrm{C}$ ) for $7.5 \mathrm{~min}$;

- Direct exposure to flame (resulting in a temperature of up to $400^{\circ} \mathrm{C}$ ) for $10 \mathrm{~min}$;

- Temperature of $230{ }^{\circ} \mathrm{C}$ for $3 \mathrm{~h}$.

The creation of a reference signal database in the acoustic emission method involves several steps. These include:

- Signal generation under laboratory conditions during the destruction of standard samples in a specified manner;

- Comparison of signals from the destruction of model samples subjected to different destruction processes;

- Verification of the reference signals generated by various types and lengths of composite panel loaded to destruction;

- Final verification on components during standard operation (this step will be performed during further tests).

The next step was to adopt the standard parameters needed to create a reference signal database, namely:

- The assumed number of destructive processes (based on literature and own research);

- Measures of distance between clusters-in this case Euclidean space with time distribution;

- The number of iterations necessary to determine the optimal number of classes ( $\mathrm{min}$. $1,000,000)$.

The reference file with four classes obtained in this way was then verified on the samples in laboratory tests with single destructive processes prevailing.

As a result of the work performed, a database of reference signals was obtained for assessing the technical condition of the panels. Using the reference signal database, the individual AE parameters are only an illustration of the processes taking place and not a source for analysis. Therefore, it is important to apply BIG DATA analyses to create "BLACK BOX", which can be used for structural health analysis by people without academic knowledge of AE.

The number of classes was imposed by a statistical software using the k-means algorithm for the analysis of AE signals based on the literature reports. Another criterion to explain the imposed number of classes was how well the individual signals matched the correct classes, which in this case was over $90 \%$.

\section{Results}

After dividing the recorded AE signals into four classes, using the $k$-means algorithm, two of the fourteen acoustic emission parameters-the signals strength and their duration -were used as illustrations of the processes taking place. Individual AE signal classes assigned, based on preliminary tests, to processes occurring in the structure of the tested material include:

- Class 1 (green colour)-micro-crack initiation;

- Class 2 (red colour)-crack development and spread;

- Class 3 (blue)-material delamination, fibre separation; 
- Class 4 (yellow colour)-fibre breakage, material deterioration;

The paper presents graphs of the descriptors over time, including their division into classes, for mock samples from each of the tested series. The results obtained for samples within the group were similar.

\subsection{AE Signal Grouping Results}

3.1.1. Signal Analysis for Research Case $\mathrm{A}_{1}$

For the sample from the $A_{1}$ (Figure 2) test case, signals of all four classes were observed from the start of each recorded waveform. The signals corresponding to the initiation of microcracks appear from the start of the test until they reach $600 \mathrm{~s}$; their power is up to $50 \mathrm{nVs}$ and their duration up to $120 \mu \mathrm{s}$. The signals linked to crack development and spread are recorded throughout the measurement and, in most cases, are characterised by a power of up to $650 \mathrm{nVs}$ and a duration of up to $2700 \mu$ s. Events corresponding to material delamination and fibre detachment were also recorded from the start of the test, but their intensity increases after $900 \mathrm{~s}$. The strength of the signals associated with the indicated processes reaches $700 \mathrm{nVs}$. In turn, the duration of events of this class reaches $3000 \mu \mathrm{s}$. The power of the signals associated with fibre breakage and component destruction is up to $1000 \mathrm{nVs}$ and their duration is generally up to $4500 \mu \mathrm{s}$.

(a)

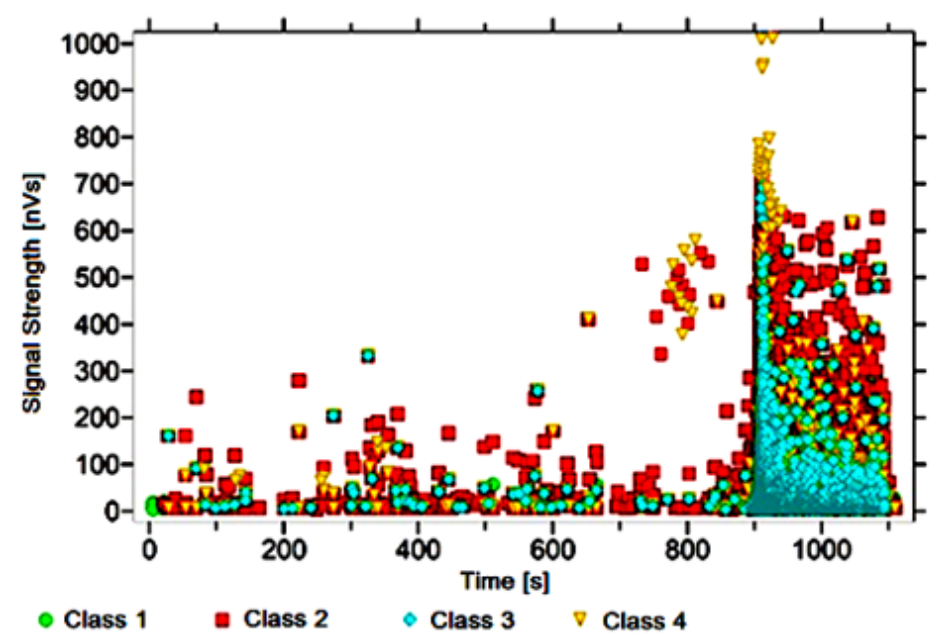

(b)

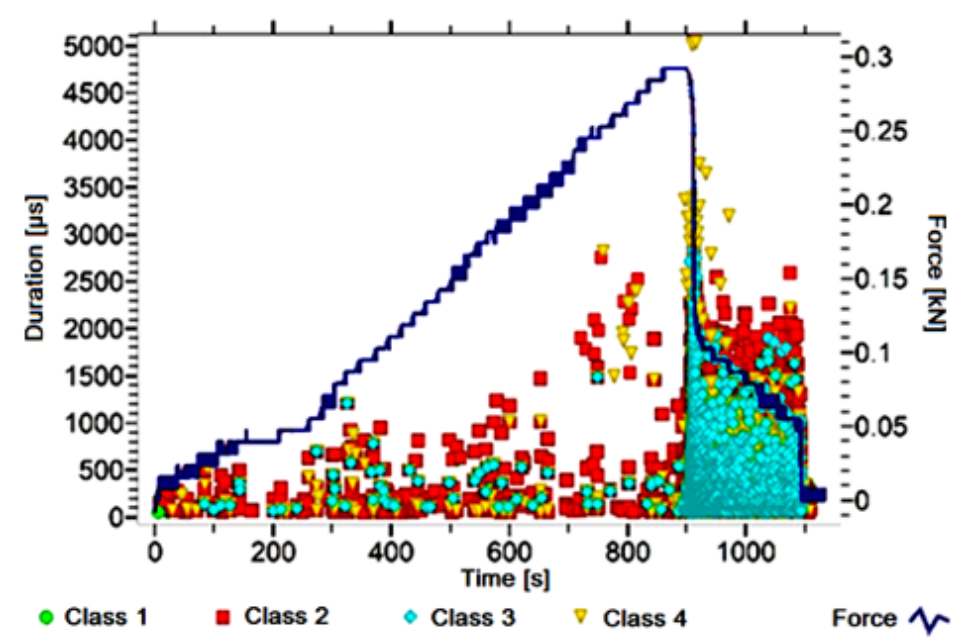

Figure 2. Graphs of acoustic emission signals for an exemplary sample of $A_{1}$ series: (a) signal strength over time; (b) distribution of the duration of the signals over time with the force increment curve. 


\subsubsection{Signal Analysis for Research Case $A_{2}$}

For the sample from the $\mathrm{A}_{2}$ (Figure 3 ) test case, signals of all four classes were observed from the start of each recorded waveform. The signals corresponding to the initiation of microcracks appear from the start of the test until they reach $650 \mathrm{~s}$; their power is up to $130 \mathrm{nVs}$ and their duration up to $200 \mu \mathrm{s}$. The signals linked to crack development and spread are recorded throughout the measurement and, in most cases, are characterised by a power of up to $550 \mathrm{nVs}$ and a duration of up to $1700 \mu \mathrm{s}$. Events corresponding to material delamination and fibre detachment were also recorded from the start of the test, but their intensity increases after $800 \mathrm{~s}$. The strength of the signals associated with the indicated processes reaches $500 \mathrm{nVs}$. In turn, the duration of events of this class reaches $2500 \mu \mathrm{s}$. The power of the signals associated with fibre breakage and component destruction is up to $700 \mathrm{nVs}$ and their duration is $4000 \mu \mathrm{s}$.

(a)

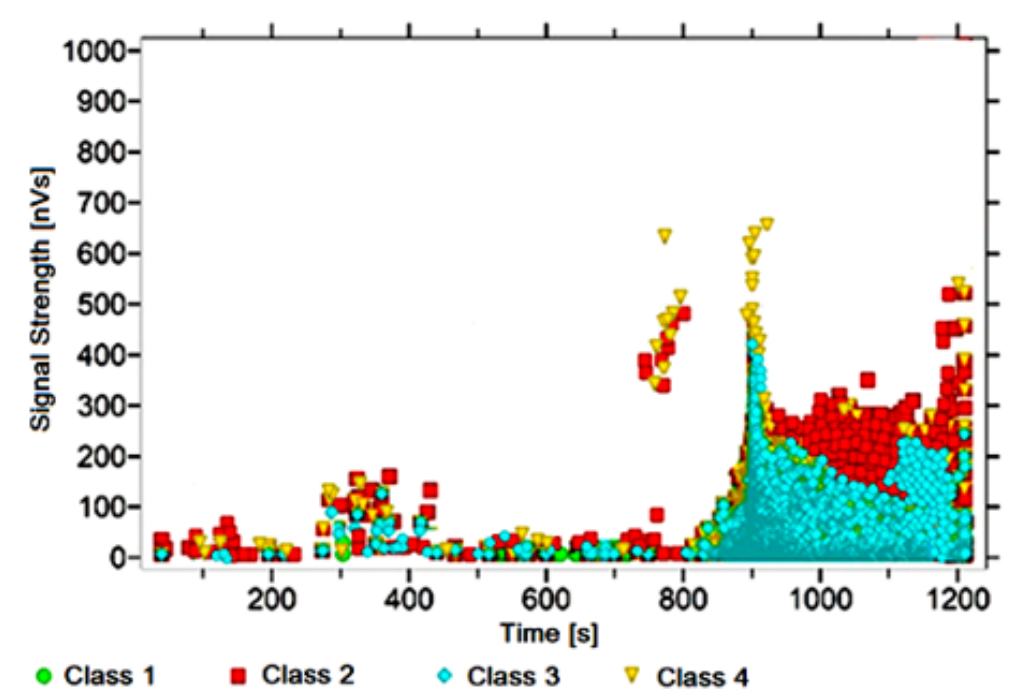

(b)

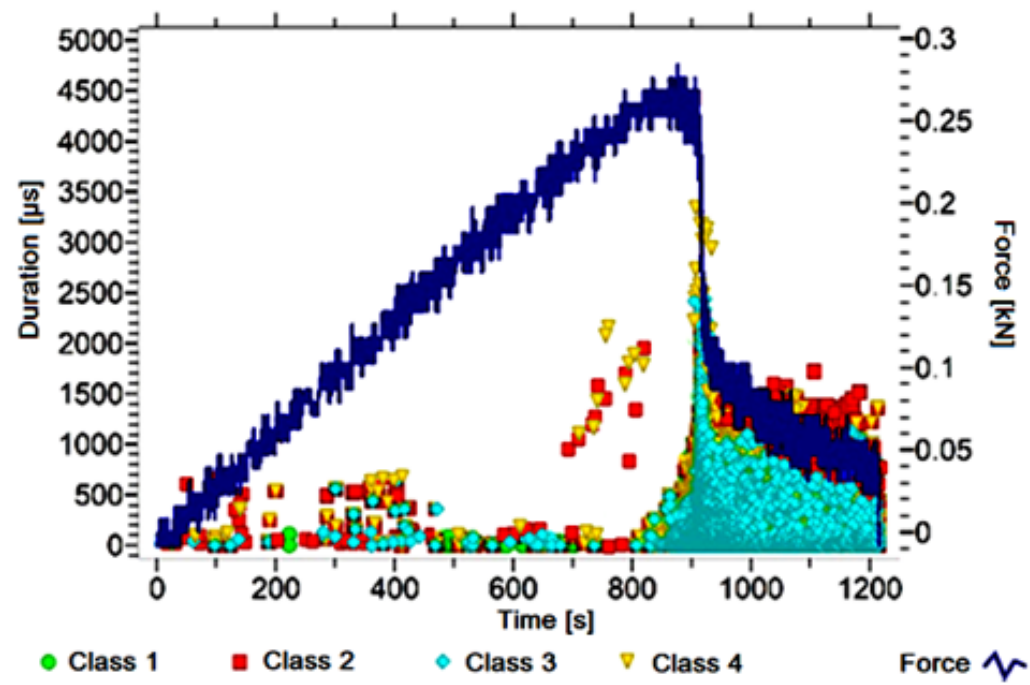

Figure 3. Graphs of acoustic emission signals for an exemplary sample of $A_{2}$ series: (a) signal strength over time; (b) distribution of the duration of the signals over time with the force increment curve.

\subsubsection{Signal Analysis for Research Case $\mathrm{A}_{3}$}

For the sample from the $\mathrm{A}_{3}$ (Figure 4) test case, signals of all four classes were observed from the start of each recorded waveform. The signals corresponding to the initiation of microcracks appear from the start of the test until they reach $1000 \mathrm{~s}$; their power is up 
to $45 \mathrm{nVs}$ and their duration up to $150 \mu \mathrm{s}$. The signals linked to crack development and spread are recorded throughout the measurement and, in most cases, are characterised by a power of up to $600 \mathrm{nVs}$ and a duration of up to $2500 \mu \mathrm{s}$. Events corresponding to material delamination and fibre detachment were also recorded from the start of the test, but their intensity increases after $1000 \mathrm{~s}$. The strength of the signals associated with the indicated processes reaches $700 \mathrm{nVs}$. In turn, the duration of events of this class reaches $2500 \mu \mathrm{s}$. The power of the signals associated with fibre breakage and component destruction is even up to $1000 \mathrm{nVs}$ and their duration is $3500 \mu \mathrm{s}$.

(a)

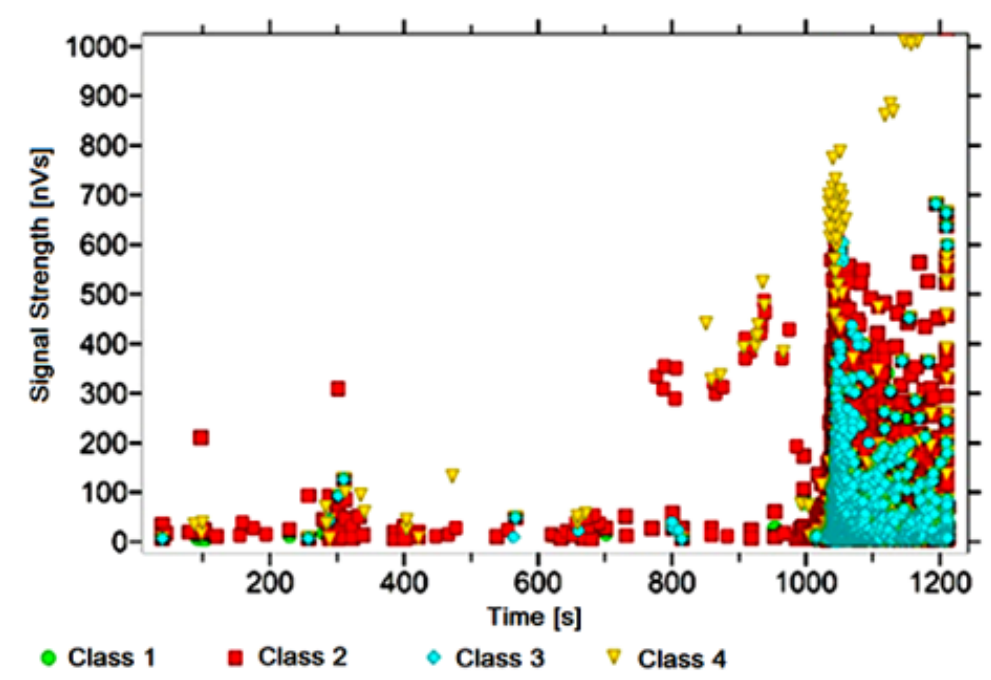

(b)

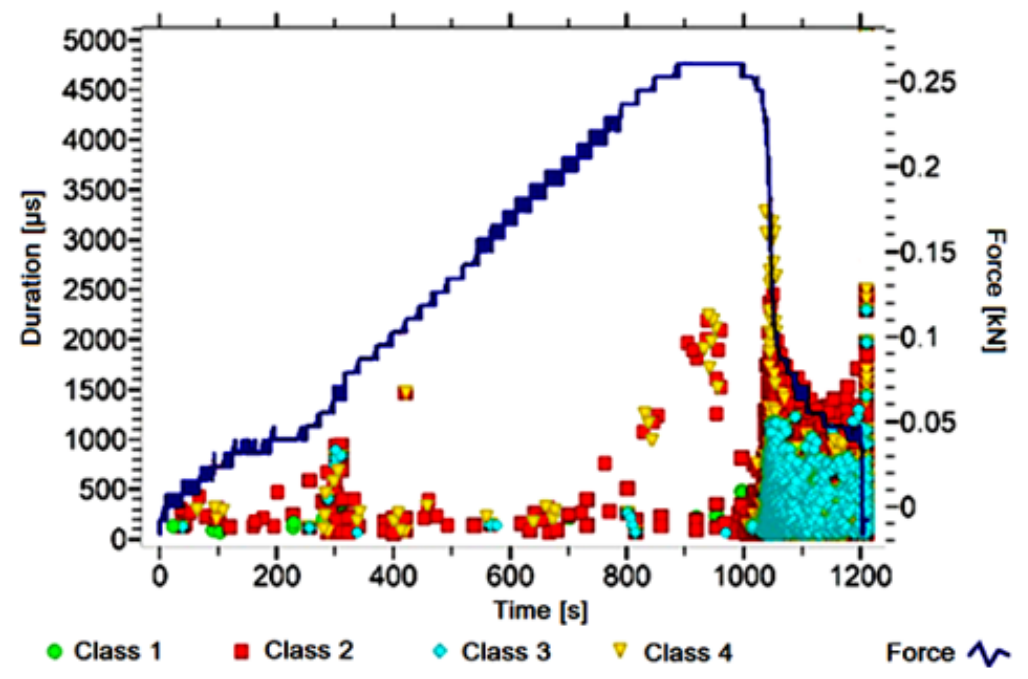

Figure 4. Graphs of acoustic emission signals for an exemplary sample of $A_{3}$ series: (a) signal strength over time; (b) distribution of the duration of the signals over time with the force increment curve.

\subsubsection{Signal Analysis for Research Case $\mathrm{A}_{4}$}

For the sample from the $\mathrm{A}_{4}$ (Figure 5) test case, signals of all four classes were observed from the start of each recorded waveform. The signals corresponding to the initiation of microcracks appear from the start of the test until they reach $600 \mathrm{~s}$; their power is up to $60 \mathrm{nVs}$ and their duration up to $200 \mu \mathrm{s}$. The signals linked to crack development and spread are recorded throughout the measurement and, in most cases, are characterised by a power of up to $500 \mathrm{nVs}$ and a duration of up to $2100 \mu$ s. Events corresponding to material delamination and fibre detachment were also recorded from the start of the test, but their intensity increases after $800 \mathrm{~s}$. The strength of the signals associated with the indicated 
processes reaches $450 \mathrm{nVs}$. In turn, the duration of events of this class reaches $2000 \mu \mathrm{s}$. The power of the signals associated with fibre breakage and component destruction is even up to $1000 \mathrm{nVs}$ and their duration is $4500 \mu \mathrm{s}$.

(a)

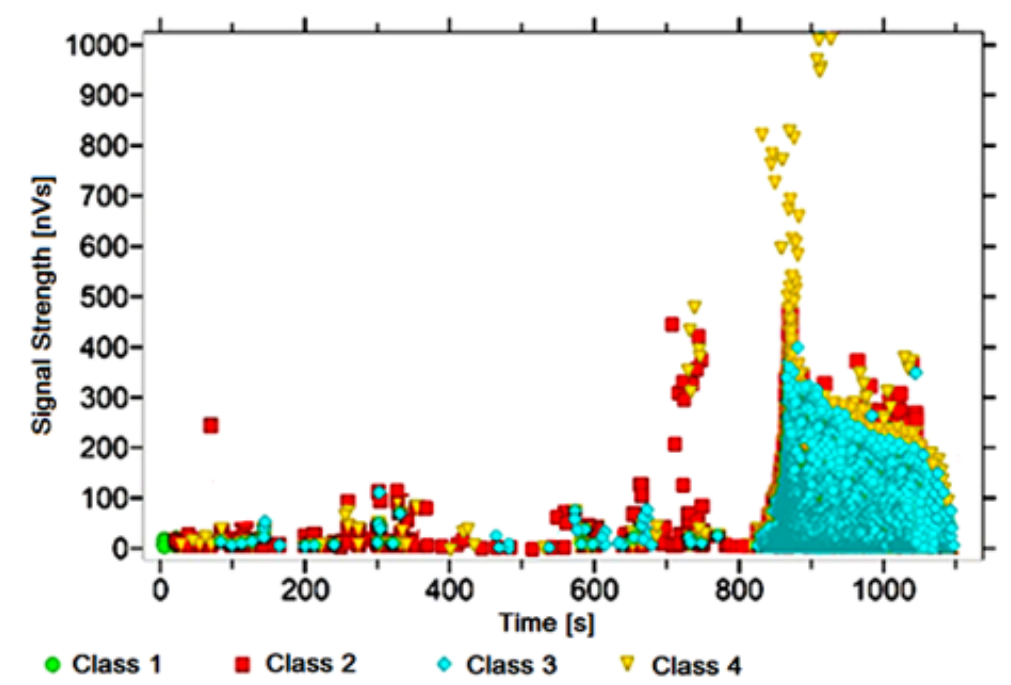

(b)

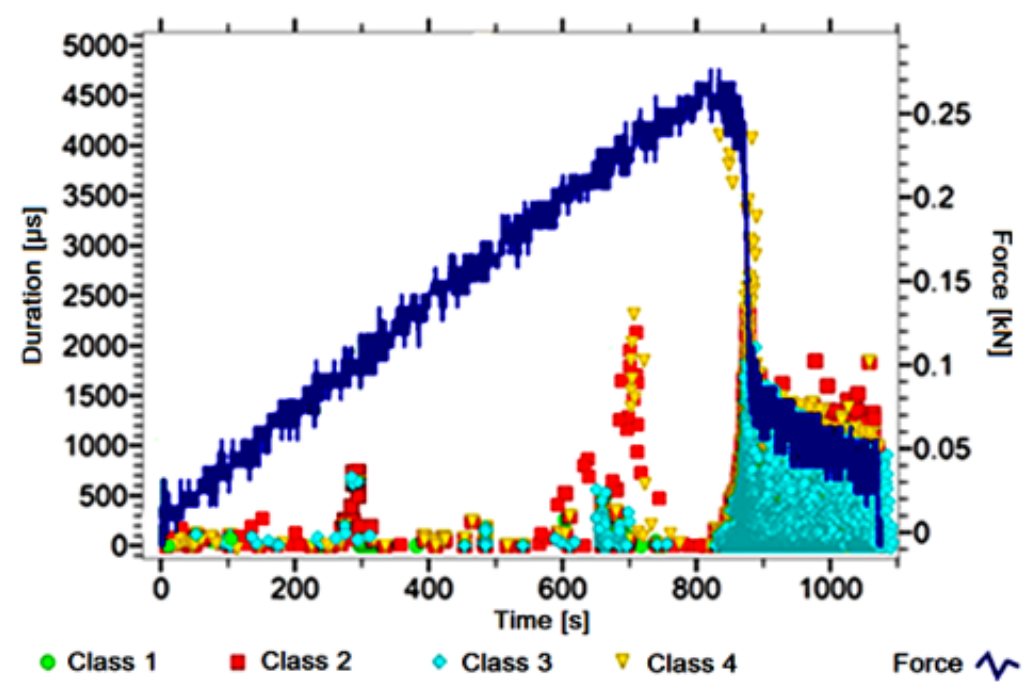

Figure 5. Graphs of acoustic emission signals for an exemplary sample of $\mathrm{A}_{4}$ series: (a) signal strength over time; (b) distribution of the duration of the signals over time with the force increment curve.

\subsubsection{Signal Analysis for Research Case $A_{5}$}

For the sample from the $\mathrm{A}_{5}$ (Figure 6) test case, signals of all four classes were observed from the start of each recorded waveform. The signals corresponding to the initiation of microcracks appear from the start of the test until they reach $400 \mathrm{~s}$; their power is up to $50 \mathrm{nVs}$ and their duration up to $150 \mu \mathrm{s}$. The signals linked to crack development and spread are recorded throughout the measurement and are characterised by a power of up to $600 \mathrm{nVs}$ and a duration of up to $2000 \mu \mathrm{s}$. Events corresponding to material delamination and fibre detachment were also recorded from the start of the test, but their intensity increases after $800 \mathrm{~s}$. The strength of the signals associated with the indicated processes reaches $800 \mathrm{nVs}$. In turn, the duration of events of this class reaches $2300 \mu \mathrm{s}$. The power of the signals associated with fibre breakage and component destruction is even up to $1000 \mathrm{nVs}$ and their duration is $3000 \mu \mathrm{s}$. 
(a)

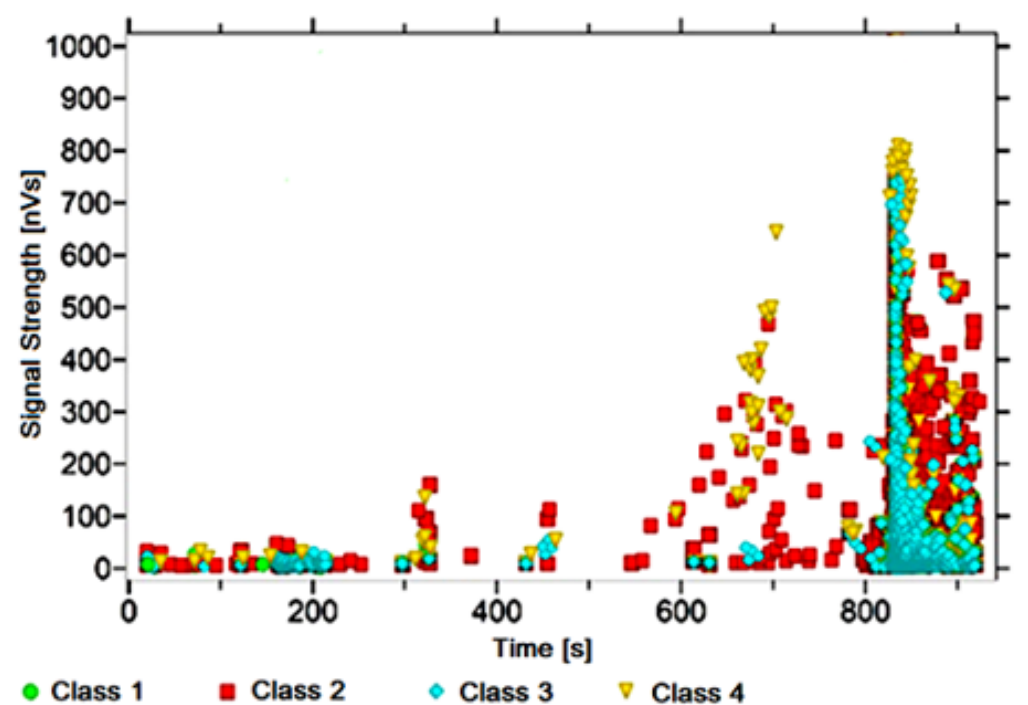

(b)

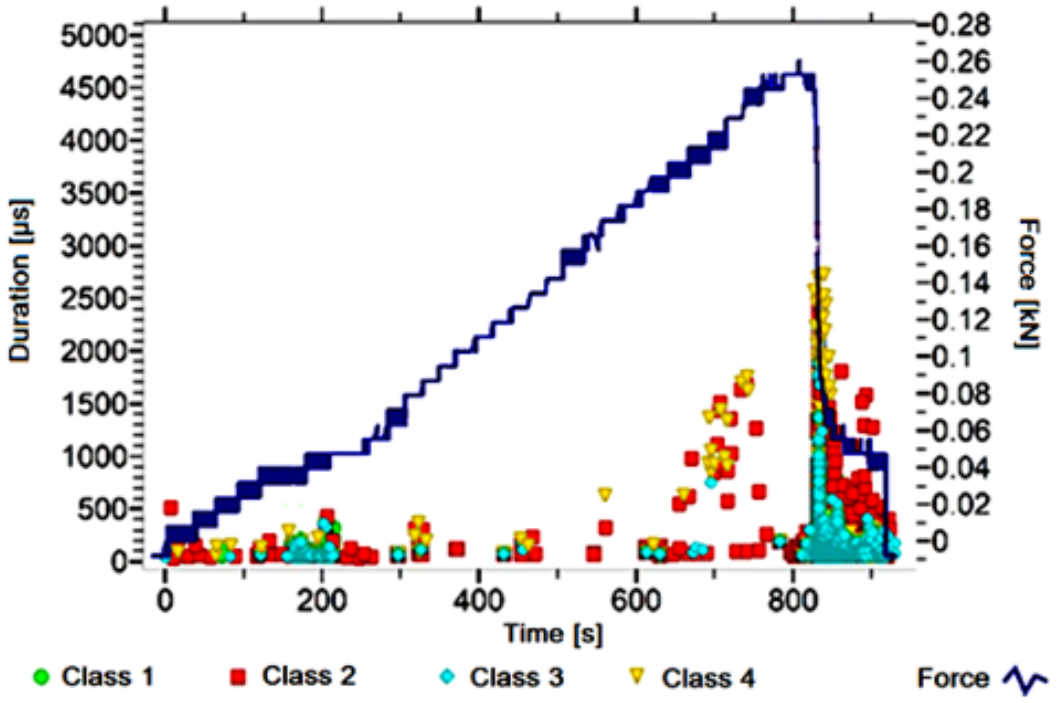

Figure 6. Graphs of acoustic emission signals for an exemplary sample of $A_{5}$ series: (a) signal strength over time; (b) distribution of the duration of the signals over time with the force increment curve.

\subsubsection{Signal Analysis for Research Case $A_{6}$}

For the sample from the $A_{6}$ (Figure 7) test case, signals of all four classes were observed from the start of each recorded waveform. The signals corresponding to the initiation of microcracks appear from the start of the test until they reach $400 \mathrm{~s}$; their power is up to $50 \mathrm{nVs}$ and their duration up to $200 \mu \mathrm{s}$. The signals linked to crack development and spread are recorded throughout the measurement and, in most cases, are characterised by a power of up to $500 \mathrm{nVs}$ and a duration of up to $2200 \mu \mathrm{s}$. Events corresponding to material delamination and fibre detachment were also recorded from the start of the test, but their intensity increases after $700 \mathrm{~s}$. The strength of the signals associated with the indicated processes reaches $400 \mathrm{nVs}$. In turn, the duration of events of this class reaches $2500 \mu \mathrm{s}$. The power of the signals associated with fibre breakage and component destruction exceeds $600 \mathrm{nVs}$ and their duration is $3000 \mu \mathrm{s}$. 
(a)

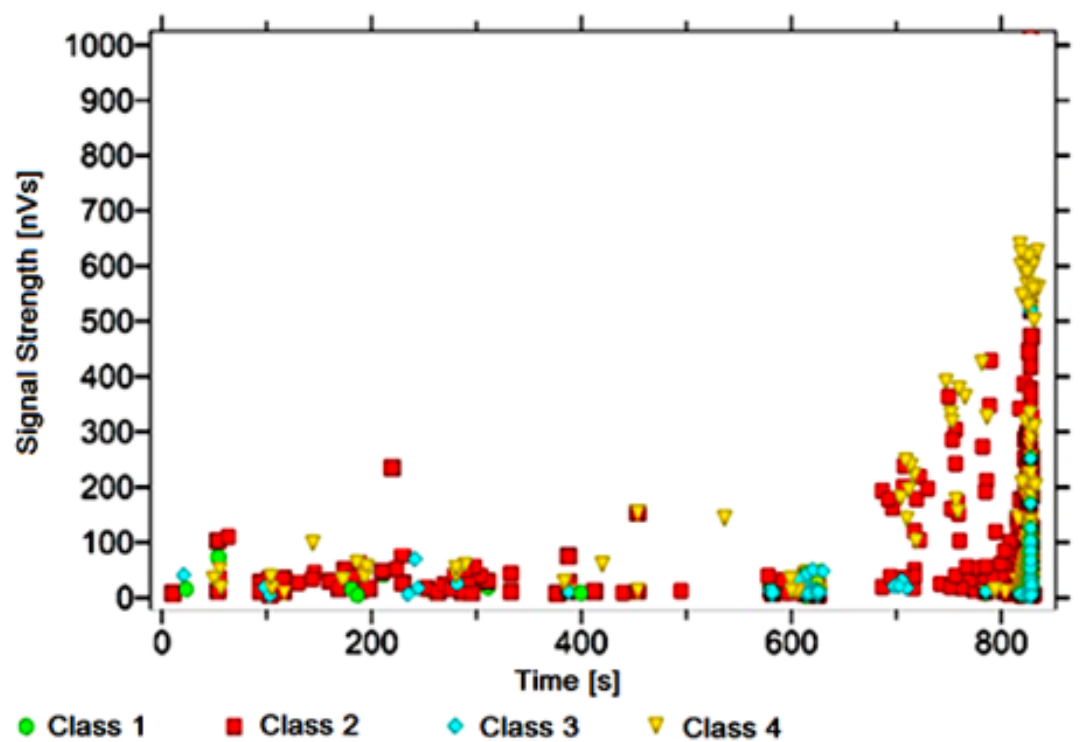

(b)

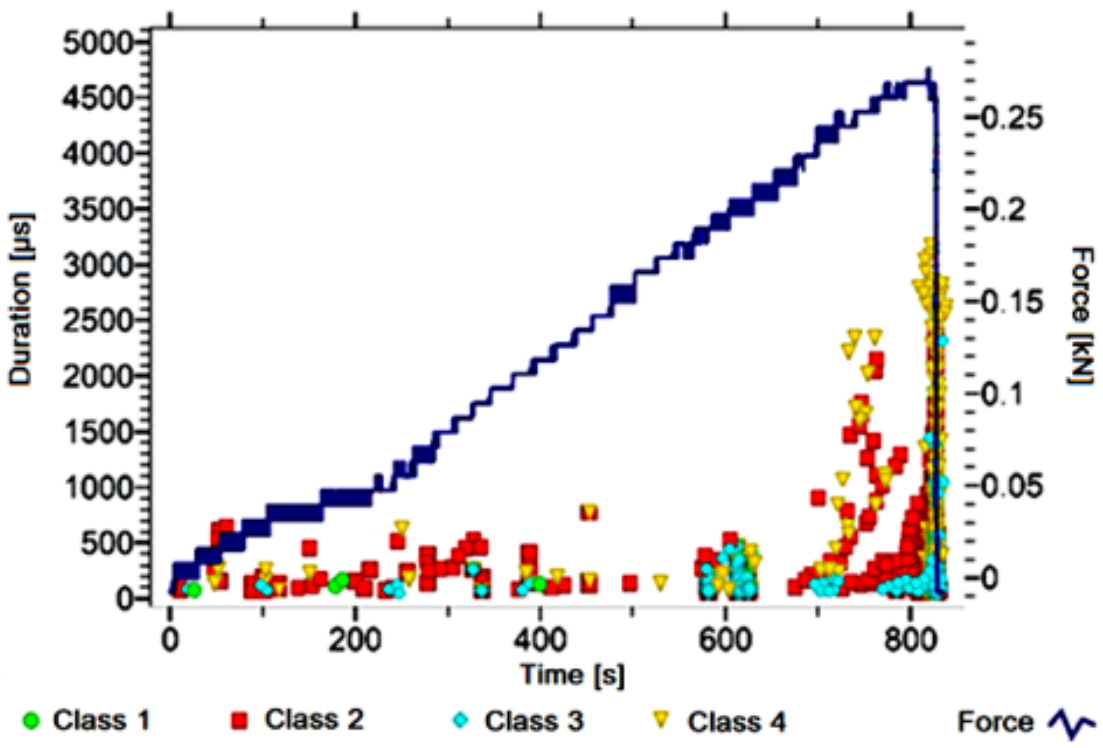

Figure 7. Graphs of acoustic emission signals for an exemplary sample of $A_{6}$ series: (a) signal strength over time; (b) distribution of the duration of the signals over time with the force increment curve.

\subsubsection{Signal Analysis for Research Case $A_{7}$}

For the sample from the $A_{7}$ (Figure 8 ) test case, signals of all four classes were observed from the start of each recorded waveform. The signals corresponding to the initiation of microcracks appear from the start of the test until they reach $700 \mathrm{~s}$; their power is up to $45 \mathrm{nVs}$ and their duration up to $170 \mu \mathrm{s}$. The signals linked to crack development and spread are recorded throughout the measurement and are characterised by a power of up to $600 \mathrm{nVs}$ and a duration of up to $2300 \mu \mathrm{s}$. Events corresponding to material delamination and fibre detachment were also recorded from the start of the test, but their intensity increases at around $800 \mathrm{~s}$. The strength of the signals associated with the indicated processes reaches $600 \mathrm{nVs}$. In turn, the duration of events of this class reaches $3000 \mu \mathrm{s}$. The power of the signals associated with fibre breakage and component destruction is even up to $1000 \mathrm{nVs}$ and their duration is $5000 \mu \mathrm{s}$. 
(a)

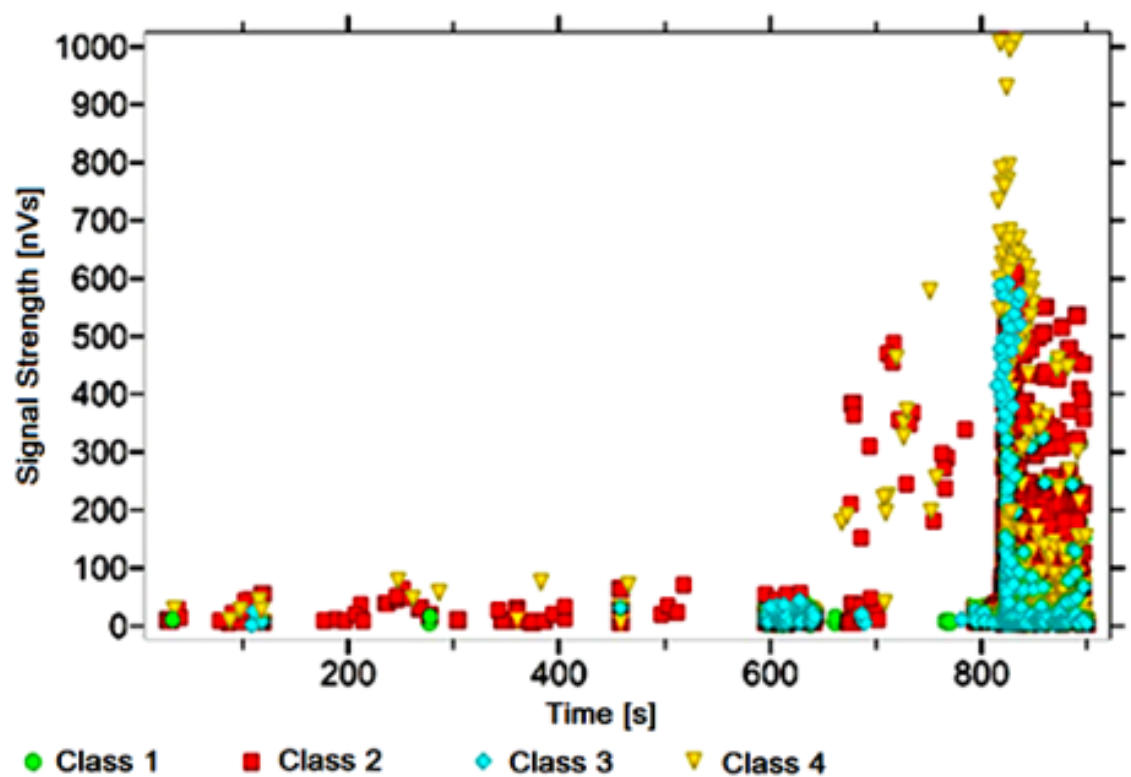

(b)

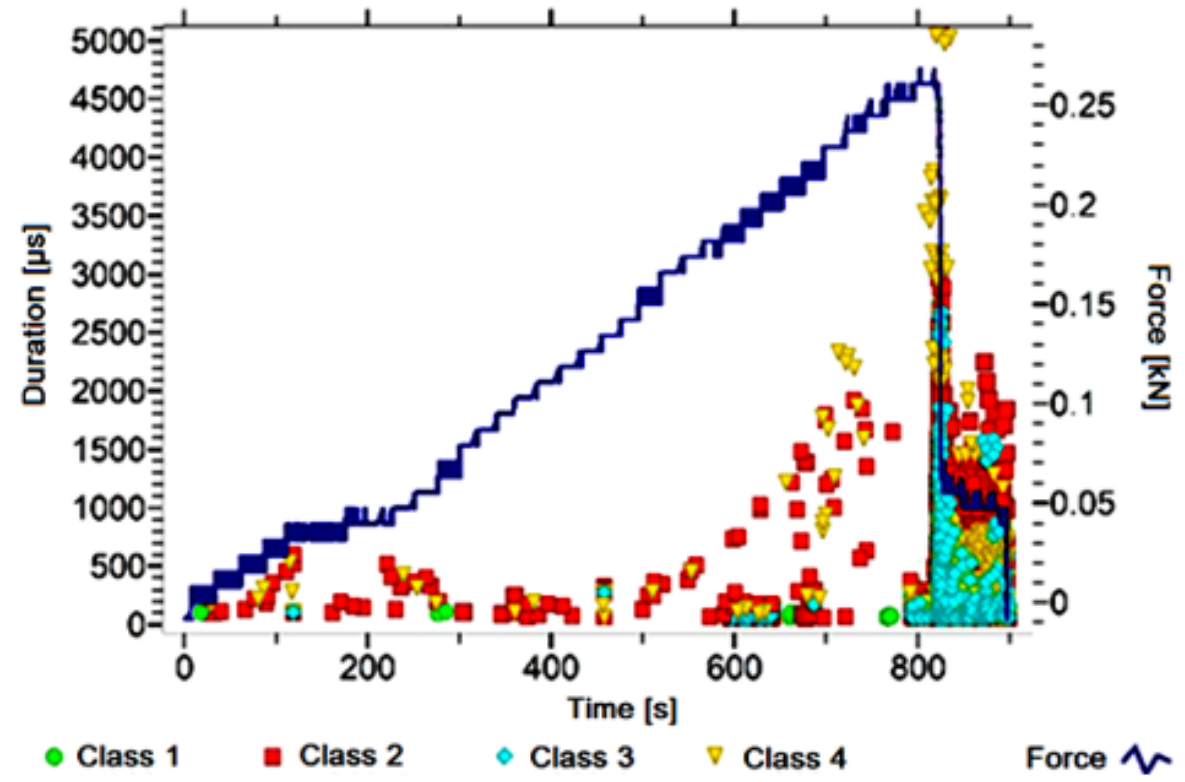

Figure 8. Graphs of acoustic emission signals for an exemplary sample of $A_{7}$ series: (a) signal strength over time; (b) distribution of the duration of the signals over time with the force increment curve.

\subsubsection{Signal Analysis for Research Case $\mathrm{A}_{8}$}

For the sample from the $A_{8}$ (Figure 9) test case, signals of all four classes were observed from the start of each recorded waveform. The signals corresponding to the initiation of microcracks appear from the start of the test until they reach $400 \mathrm{~s}$; their power is up to $50 \mathrm{nVs}$ and their duration up to $130 \mu \mathrm{s}$. The signals linked to crack development and spread are recorded throughout the measurement and are characterised by a power of up to $600 \mathrm{nVs}$ and a duration of up to $2000 \mu \mathrm{s}$. Events corresponding to material delamination and fibre detachment were also recorded from the start of the test, but their intensity increases after $800 \mathrm{~s}$. The strength of the signals associated with the indicated processes reaches $600 \mathrm{nVs}$. In turn, the duration of events of this class reaches $2500 \mu \mathrm{s}$. The power of the signals associated with fibre breakage and component destruction is even up to $1000 \mathrm{nVs}$ and their duration is $3000 \mu \mathrm{s}$. 
(a)

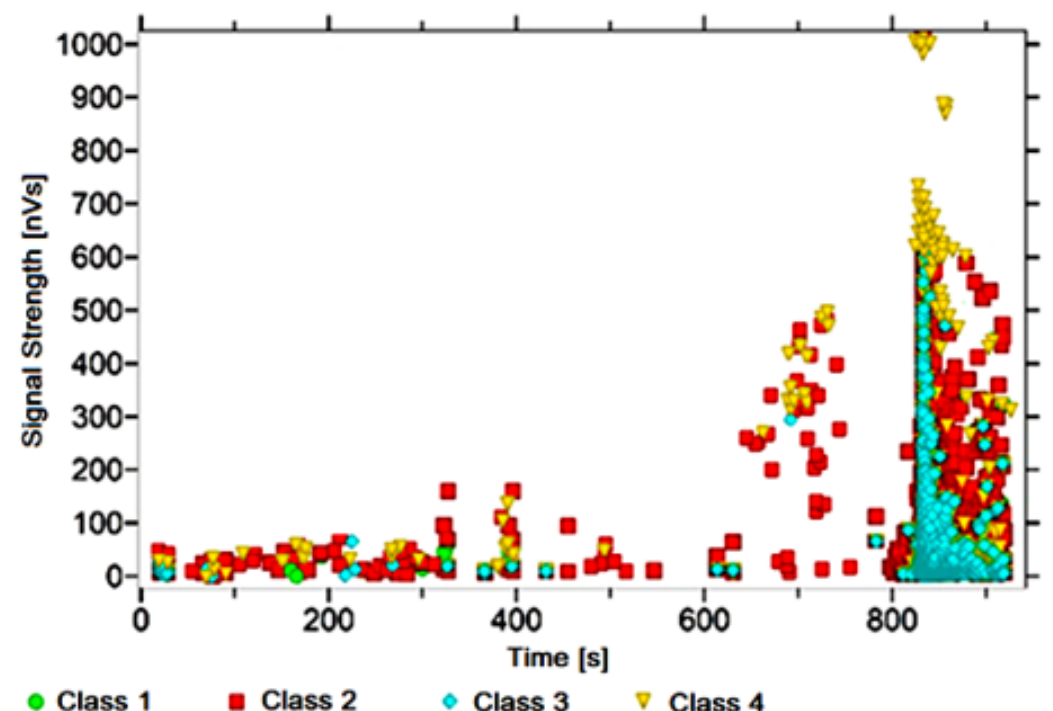

(b)

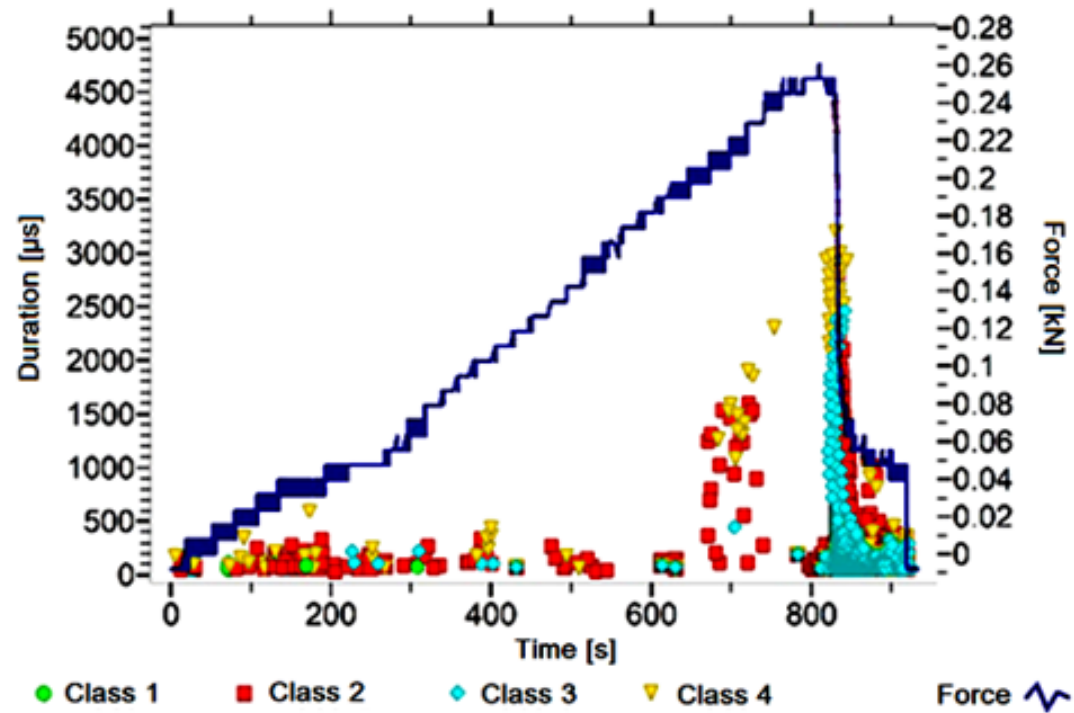

Figure 9. Graphs of acoustic emission signals for an exemplary sample of $A_{8}$ series: (a) signal strength over time; (b) distribution of the duration of the signals over time with the force increment curve.

\subsubsection{Signal Analysis for Research Case $A_{9}$}

For the sample from the $A_{9}$ (Figure 10) test case, signals of all four classes were observed from the start of each recorded waveform. The signals corresponding to the initiation of microcracks appear from the start of the test until they reach $500 \mathrm{~s}$; their power is up to $60 \mathrm{nVs}$ and their duration up to $250 \mu \mathrm{s}$. The signals linked to crack development and spread are recorded throughout the measurement and are characterised by a power of up to $700 \mathrm{nVs}$ and a duration of up to $2500 \mu \mathrm{s}$. Events corresponding to material delamination and fibre detachment were also recorded from the start of the test, but their intensity increases at around $800 \mathrm{~s}$. The strength of the signals associated with the indicated processes reaches $700 \mathrm{nVs}$. In turn, the duration of events of this class reaches $3000 \mu \mathrm{s}$. The power of the signals associated with fibre breakage and component destruction reaches up to $800 \mathrm{nVs}$ and their duration is $4000 \mu \mathrm{s}$. 
(a)

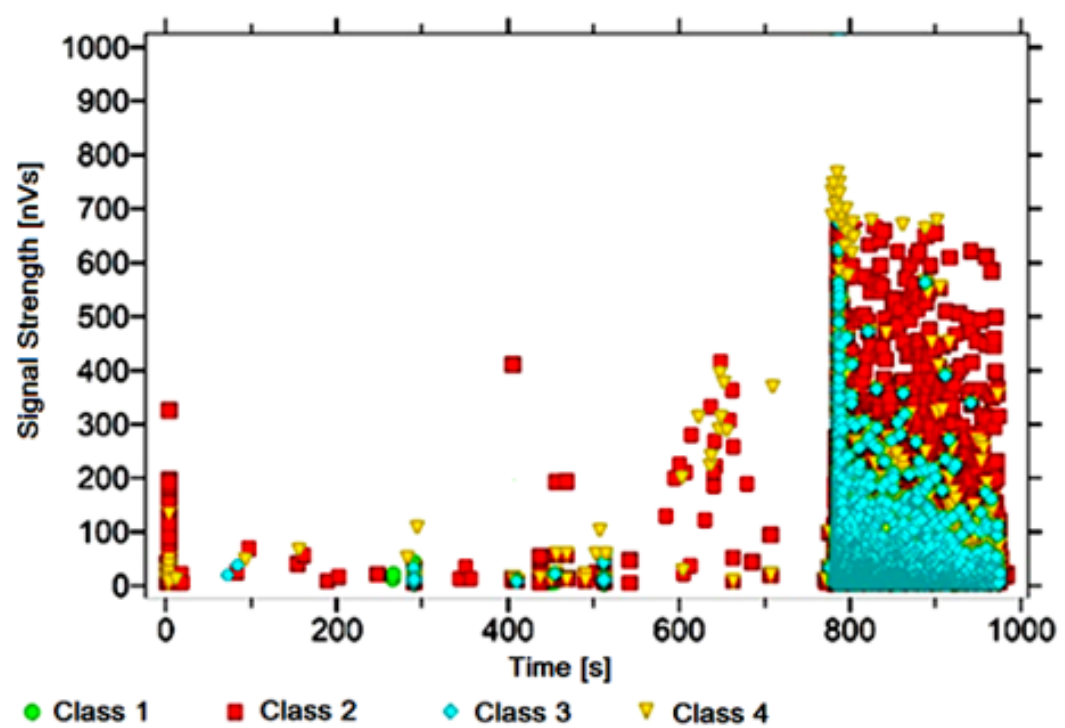

(b)

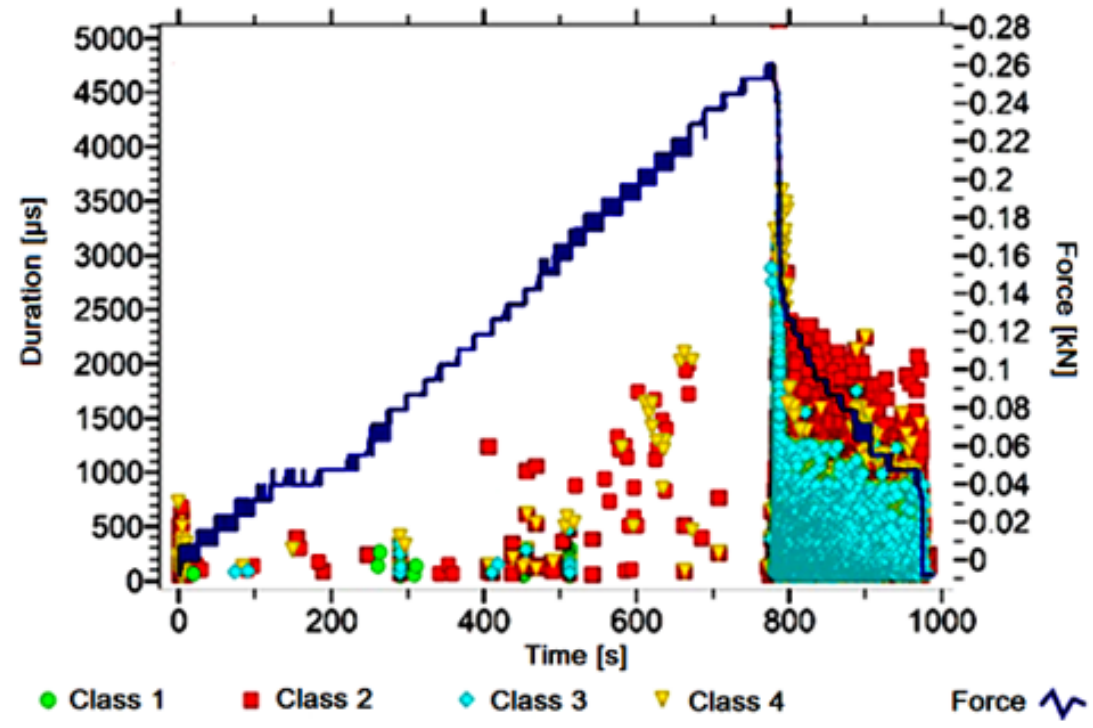

Figure 10. Graphs of acoustic emission signals for an exemplary sample of $A_{9}$ series: (a) signal strength over time; (b) distribution of the duration of the signals over time with the force increment curve.

\subsubsection{Signal Analysis for Research Case $A_{10}$}

For the sample from the $A_{10}$ (Figure 11) test case, signals of 1 and 2 classes were observed from the start of each recorded waveform. Class 3 and 4 signals are intensified at around $400 \mathrm{~s}$. Signals corresponding to the initiation of microcracks occur up to about $400 \mathrm{~s}$; their power is up to $50 \mathrm{nVs}$ and their duration up to $250 \mu \mathrm{s}$. The signals linked to crack development and spread are recorded throughout the measurement and are characterised by a power of up to $500 \mathrm{nVs}$ and a duration of up to $2500 \mu \mathrm{s}$. The intensity of events corresponding to material delamination and fibre detachment increases after $400 \mathrm{~s}$. The strength of the signals associated with the indicated processes reaches $200 \mathrm{nVs}$. In turn, the duration of events of this class is $1300 \mu \mathrm{s}$. The power of the signals associated with fibre breakage and component destruction is up to $300 \mathrm{nVs}$ and their duration is up $1500 \mu \mathrm{s}$. 
(a)

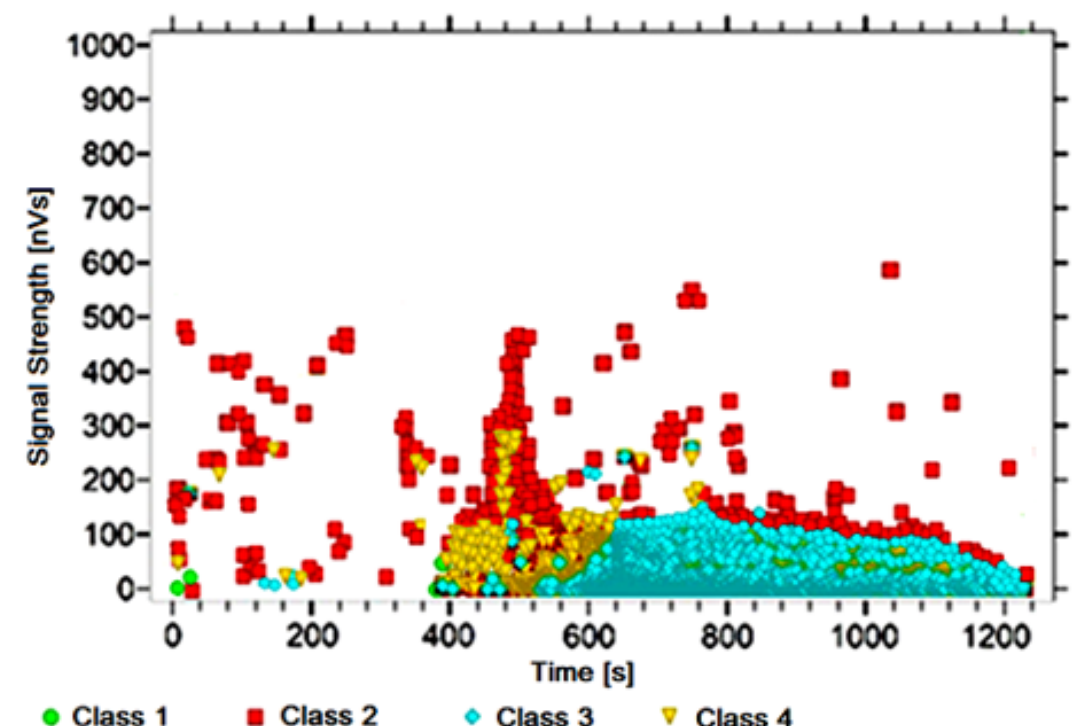

(b)

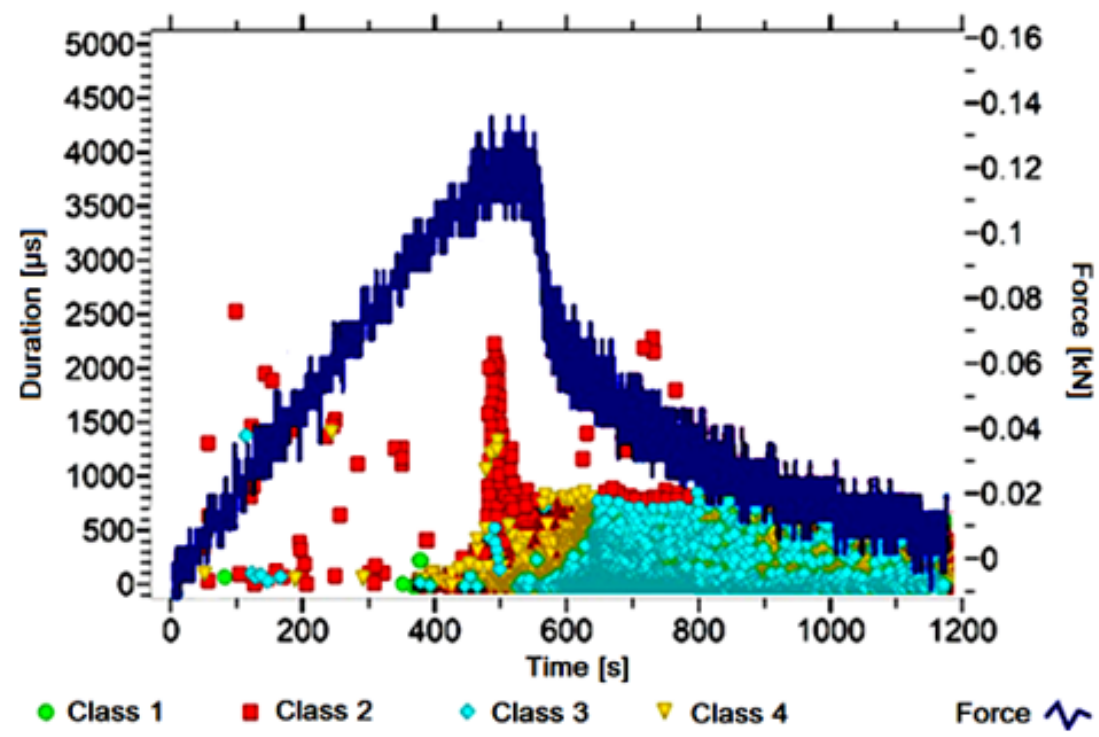

Figure 11. Graphs of acoustic emission signals for an exemplary sample of $A_{10}$ series: (a) signal strength over time; (b) distribution of the duration of the signals over time with the force increment curve.

\subsubsection{Signal Analysis for Research Case $A_{11}$}

For the sample from the $A_{11}$ (Figure 12) test case, signals of 1 and 2 classes were observed for the majority of each of the recorded waveforms. Single class 3 and 4 signals start to appear around $400 \mathrm{~s}$ and are emitted when the sample is destroyed. Few signals corresponding to the initiation of microcracks appear from the start of the test until they reach $200 \mathrm{~s}$; their power is up to $170 \mathrm{nVs}$ and their duration up to $250 \mu \mathrm{s}$. The signals linked to crack development and spread are recorded throughout the measurement and are characterised by a power of up to $600 \mathrm{nVs}$ and a duration of even up to $2500 \mu \mathrm{s}$. Events corresponding to material delamination and fibre detachment are characterised by up to $600 \mathrm{nVs}$ and have a duration of $1500 \mu \mathrm{s}$. The power of the signals linked with fibre breakage and component destruction reaches $600 \mathrm{nVs}$ and their duration is $1700 \mu \mathrm{s}$. 
(a)

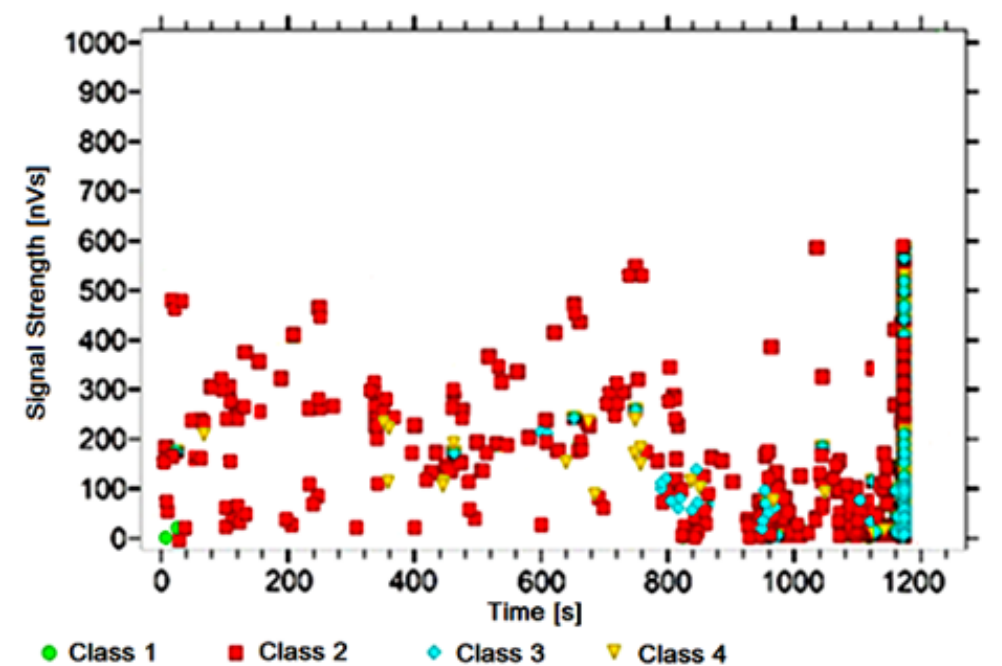

(b)

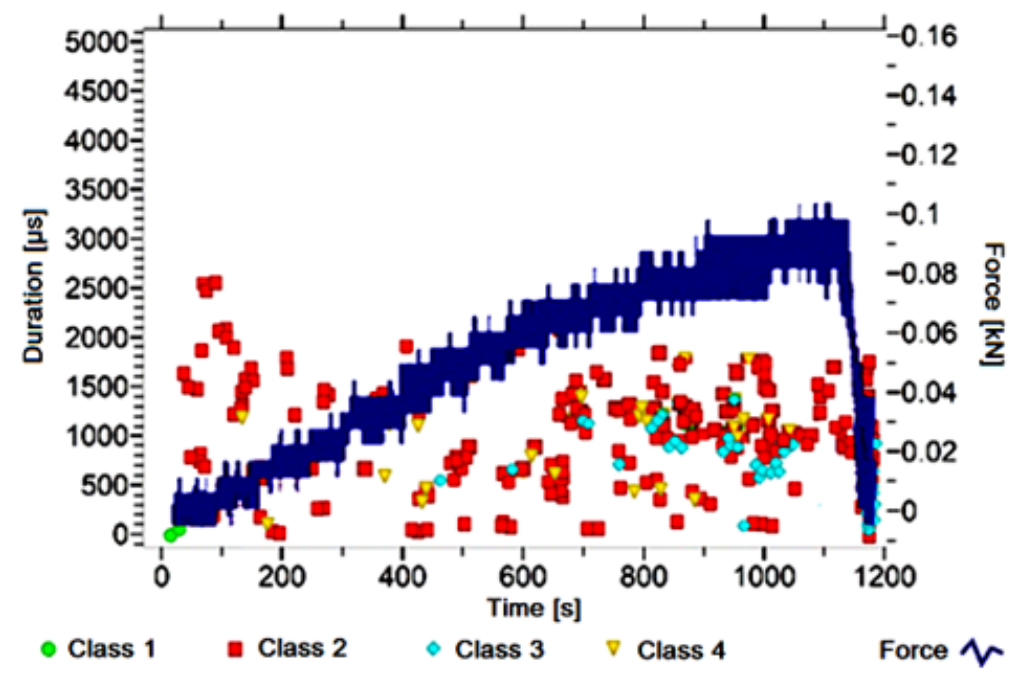

Figure 12. Graphs of acoustic emission signals for an exemplary sample of $A_{11}$ series: (a) signal strength over time; (b) distribution of the duration of the signals over time with the force increment curve.

\subsubsection{Signal Analysis for Research Case $\mathrm{A}_{12}$}

For the sample from the $A_{12}$ (Figure 13) test case, signals of 1 and 2 classes were observed for the majority of each of the recorded waveforms. Single 3 and 4 class signals are emitted after $100 \mathrm{~s}$. Few signals corresponding to the initiation of microcracks appear from the start of the test until they reach $200 \mathrm{~s}$; their power is up to $250 \mathrm{nVs}$ and their duration up to $300 \mu \mathrm{s}$. The signals linked to crack development and spread are recorded throughout the measurement and are characterised by a power of up to $600 \mathrm{nVs}$ and a duration of even up to $2500 \mu \mathrm{s}$. Events corresponding to material delamination and fibre detachment are characterised by up to $250 \mathrm{nVs}$ and have a duration of $1300 \mu \mathrm{s}$. The power of the signals linked with fibre breakage and component destruction reaches $250 \mathrm{nVs}$ and their duration is $1300 \mu \mathrm{s}$. 
(a)

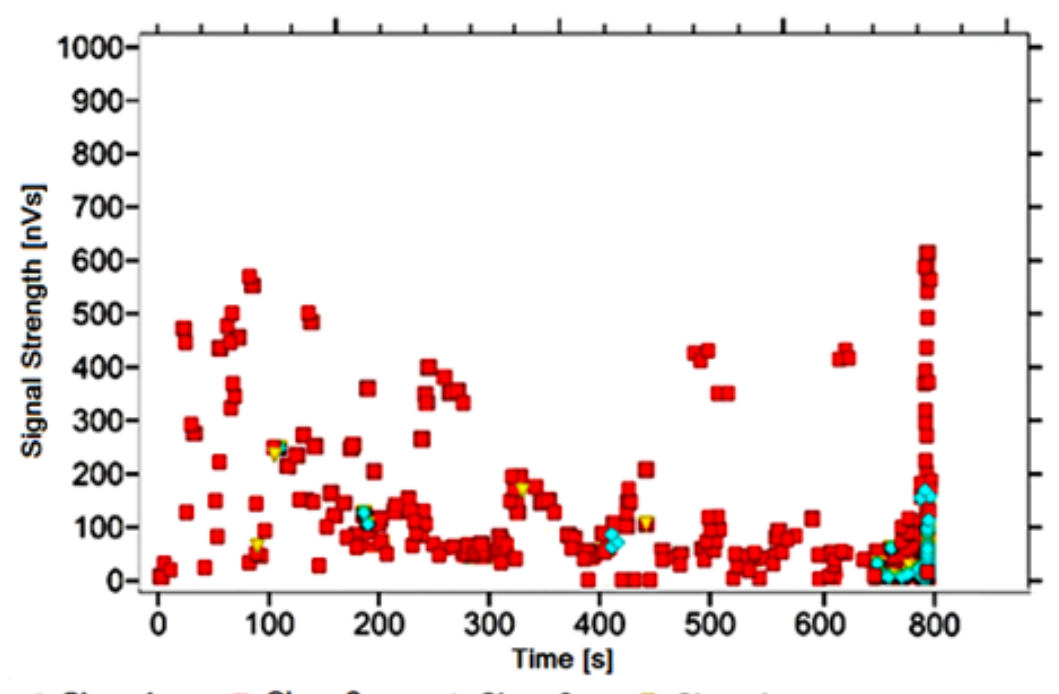

- Class $1 \quad$ Class $2 \quad \bullet$ Class $3 \quad \nabla$ Class 4

(b)

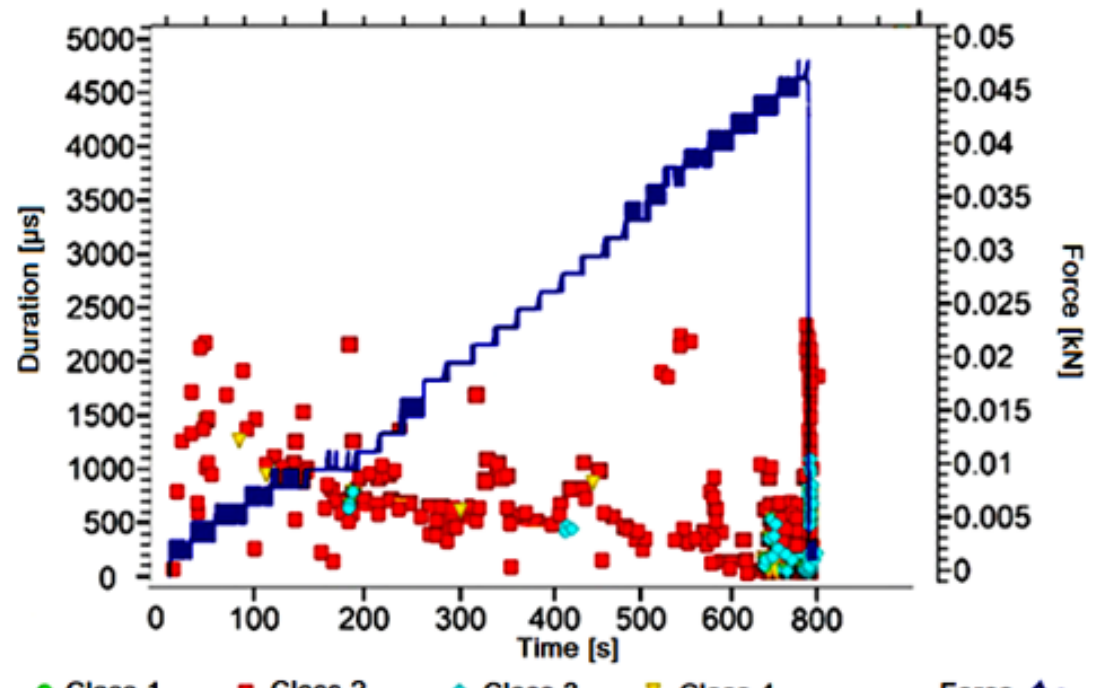

$\circ$ Class $1 \quad$ Class $2 \quad$ Class $3 \quad \nabla$ Class $4 \quad$ Force $\mathfrak{}$

Figure 13. Graphs of acoustic emission signals for an exemplary sample of A12 series: (a) signal strength over time; (b) distribution of the duration of the signals over time with the force increment curve.

\subsubsection{Signal Analysis for Research Case $A_{13}$}

For the sample from the $\mathrm{A}_{13}$ (Figure 14) test case, signals of class 2 were observed for the majority of the waveform observed. The number of class 1 and 3 signals is small. No class 4 signals were recorded. The few signals corresponding to the initiation of microcracks are characterised by a power of $20 \mathrm{nVs}$ and a duration of up to $120 \mu \mathrm{s}$. The signals linked to crack development and spread are recorded throughout the measurement and are characterised by a power of up to $550 \mathrm{nVs}$ and a duration of even up to $2500 \mu \mathrm{s}$. Events corresponding to material delamination and fibre detachment are characterised by up to $100 \mathrm{nVs}$ and have a duration of $700 \mu \mathrm{s}$. 
(a)

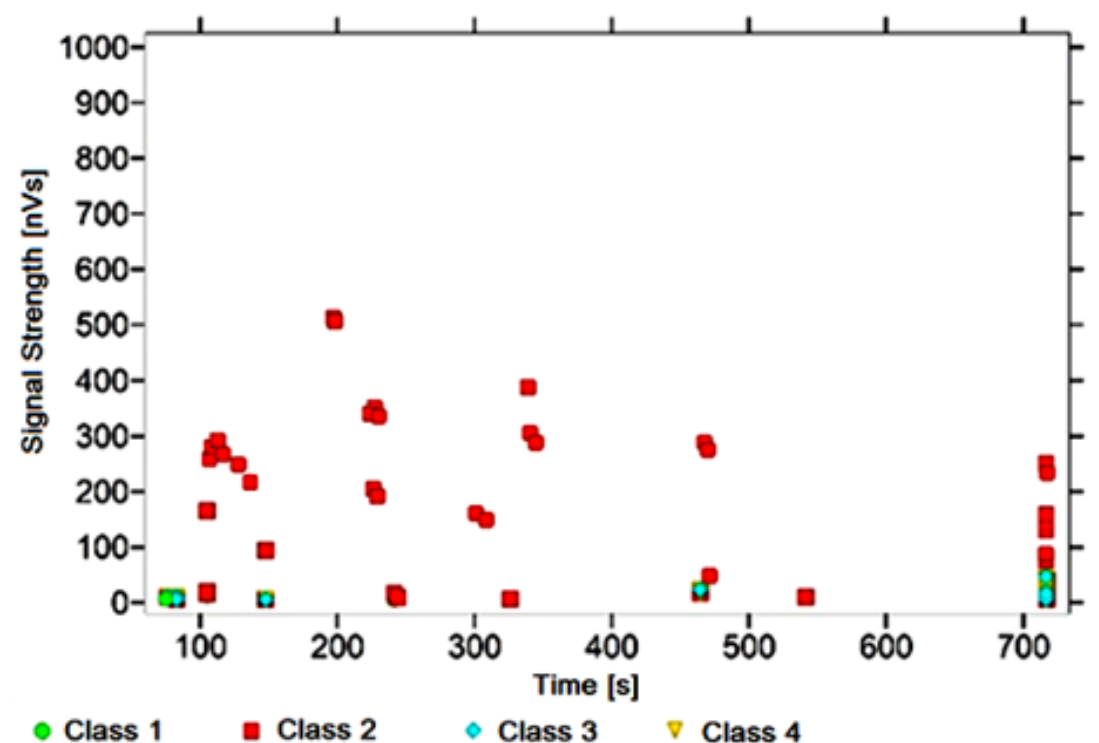

(b)

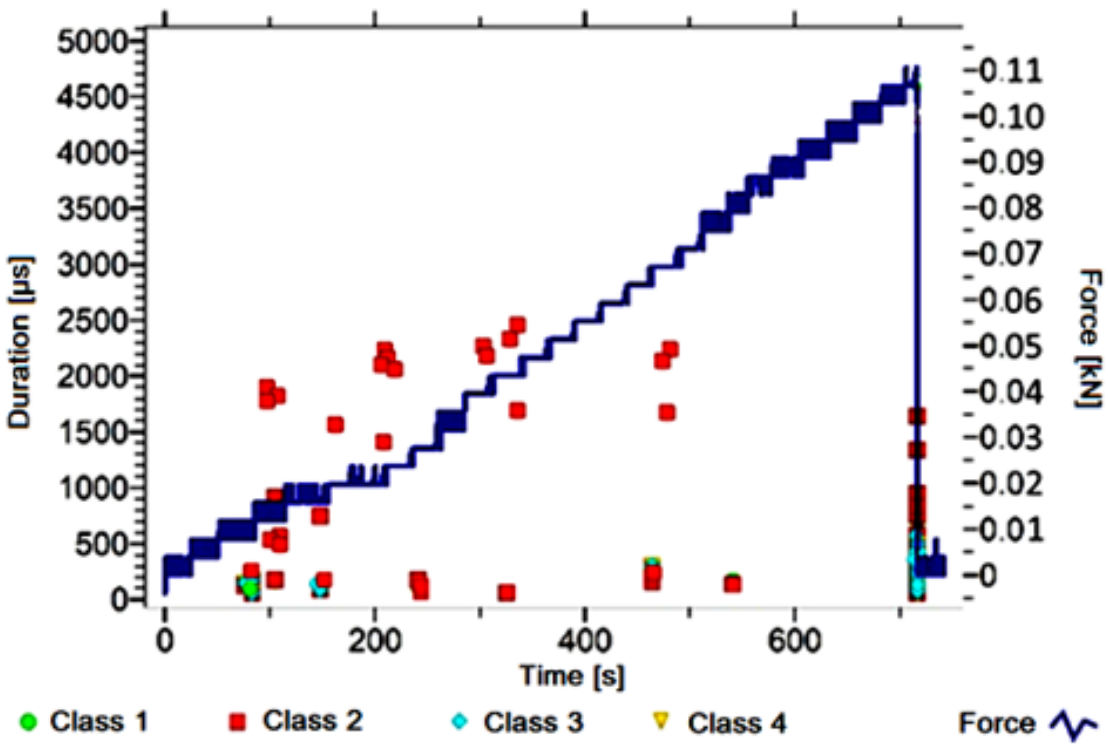

Figure 14. Graphs of acoustic emission signals for an exemplary sample of $A_{13}$ series: (a) signal strength over time; (b) distribution of the duration of the signals over time with the force increment curve.

\subsubsection{Signal Analysis for Research Case $\mathrm{A}_{14}$}

For the sample from the $\mathrm{A}_{14}$ (Figure 15) test case, signals of class 2 were observed for the majority of the waveform observed. Single class 3 signals begin to appear after $200 \mathrm{~s}$. The presence of class 1 and 4 signals was not recorded. The signals linked to crack development and spread are recorded throughout the measurement and are characterised by a power of up to $600 \mathrm{nVs}$ and a duration of even up to $2500 \mu \mathrm{s}$. Events corresponding to material delamination and fibre detachment are characterised by up to $350 \mathrm{nVs}$ and have a duration of up to $1000 \mu \mathrm{s}$. 
(a)

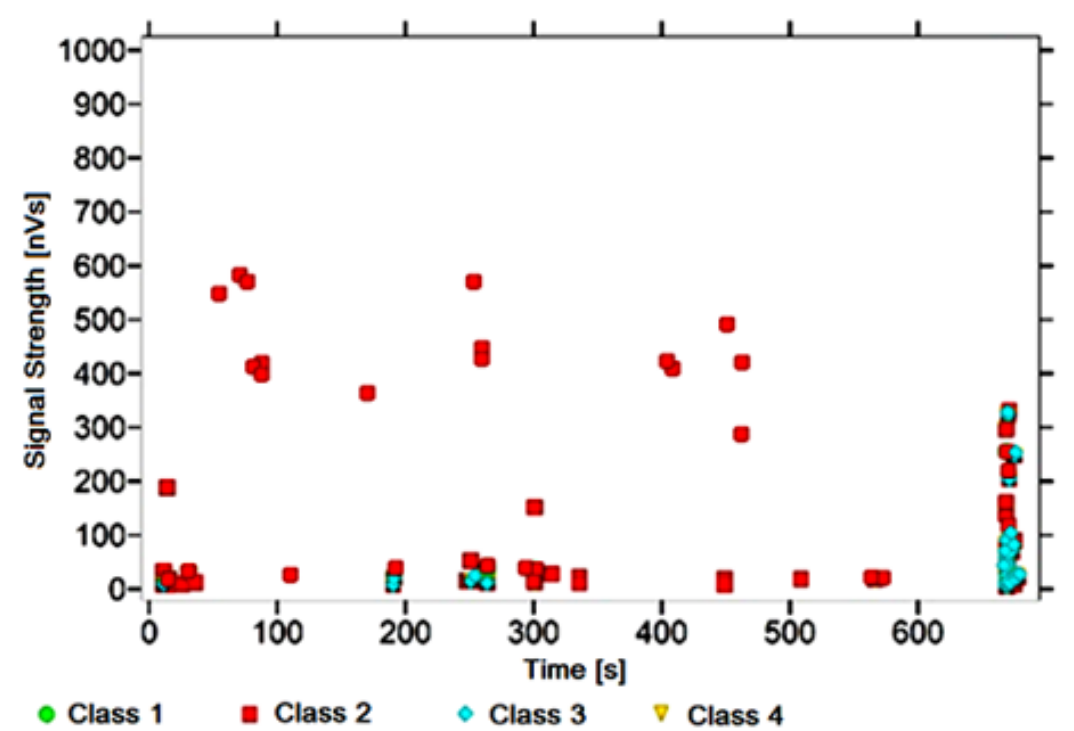

(b)

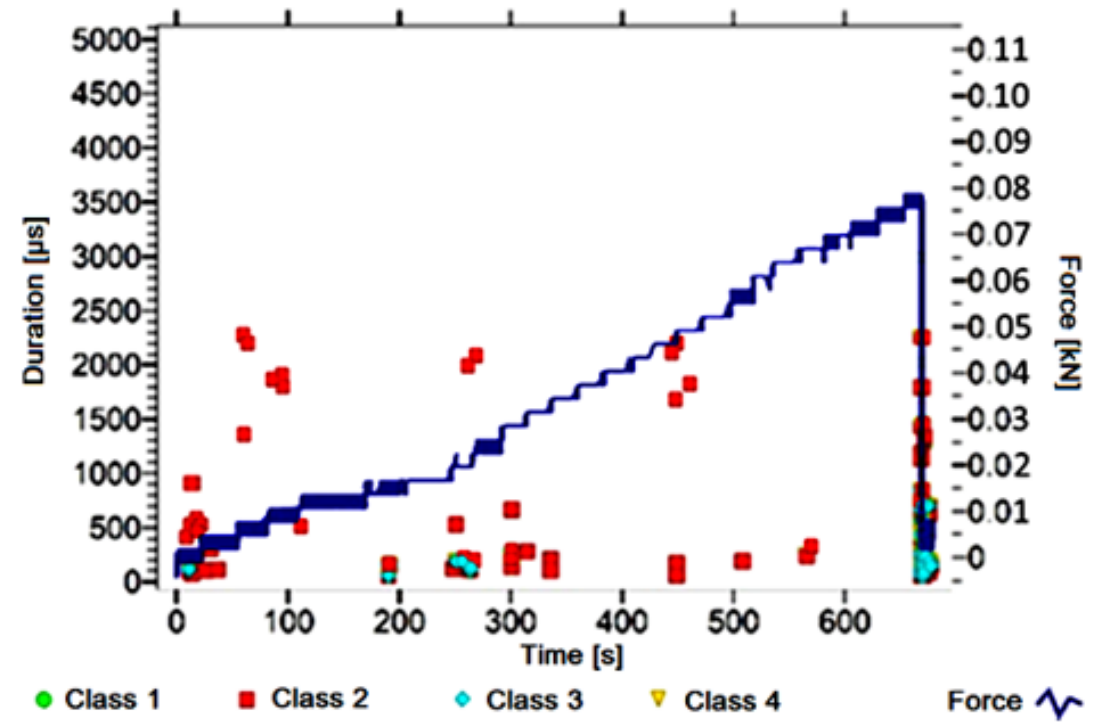

Figure 15. Graphs of acoustic emission signals for an exemplary sample of $A_{14}$ series: (a) signal strength over time; (b) distribution of the duration of the signals over time with the force increment curve.

\subsubsection{Summary of Signal Analysis}

Analysing Figures 2-15, it can be seen that for samples in the air-dry state and exposed to environmental factors $\left(A_{1}-A_{9}\right)$ there are signals of all classes from the beginning of the external load action. Shortly after applying the force, class 3 signals begin to appear, indicating that the structural delimination and fibre detachment from the matrix have begun. As the cracks in the tensile zone progresses and the crack deepens, class 4 signals for gradual fibre breakage and material deterioration start to appear at the bottom of the sample. Exceeding the stress limits in the material results in a rapid increase in the recorded descriptors.

For the samples exposed to direct fire $\left(\mathrm{A}_{10}-\mathrm{A}_{13}\right)$ and high temperature $\left(\mathrm{A}_{14}\right)$, the flame interaction did not affect the nature of the signals recorded for the samples torched for $2.5 \mathrm{~min}\left(\mathrm{~A}_{10}\right)$, while the prevailing class 2 signals were observed in the other recorded time courses. The author linked this fact to the potential for damage or degradation of the reinforcing fibres when exposed to fire and temperature, which implied a change in 
the deterioration of the components. It was found that dry samples and samples exposed to environmental conditions, due to the presence of reinforcing fibres, were destroyed by exceeding tensile stresses. On the other hand, the deterioration process of the samples exposed to temperature fluctuations, caused by probable fibre degradation, was caused by exceeding the shear strength. The analysis of the characteristics of the recorded descriptors also revealed that, during the bending of the torched and burned samples, the occurrence of most $\mathrm{AE}$ events was associated with the emission of signals with lower power (below $600 \mathrm{nVs}$ ) than those of the other groups.

Analysing the classes of $\mathrm{AE}$ signals present in the analysed waveforms of $\mathrm{A}_{11}-\mathrm{A}_{14}$ samples, it was found that the absence of class 1 signals in the initial phase of testing indicates the potential presence of locally weakened structure of cement-fibre panels. The absence of the class 3 and 4 signals in the recorded events clearly indicates damage to the reinforcing fibres or the potential delamination and voids in the material structure.

\subsection{Statistical Analysis of the Obtained Results}

During statistical analysis of received results, for all samples, first, all data were pre-tested in order to select the appropriate test groups to examine the data. The groups examined are approximately equinumerous. Therefore, standard distributions of data in individual groups were examined with the Shapiro-Wilk test. For most data, no grounds to reject the hypothesis of standard distribution were found. The Levene test was then performed to examine the homogeneity of variance.

In most groups there is no homogeneous variance. Therefore, in order to examine the distributions, it was decided to use the non-parametric test for Kruskal-Wallis independent variables.

The below charts provide graphical results of the Kruskal-Wallis test.

3.2.1. Kruskal-Wallis Test Results for Independent Samples of the Number of Class 1 Signals

Analysing the graphical representation of the Kruskal-Wallis test results for independent samples of the number of class 1 signals (Figure 16), it can be observed that the maximum number of signals of this class was recorded for panels from the $A_{6}$ test case (frozen-thawed samples for 10 cycles). For this case there was also the largest scatter of results. The $A_{8}$ test cases (frozen-thawed samples for 50 cycles) and $A_{9}$ (torched samples for 100 cycles) contain single statistical outliers. The lowest values of the class 1 signal number were recorded for the $\mathrm{A}_{13}$ test cases (torched samples for $10 \mathrm{~min}$ ) and $\mathrm{A}_{14}$ (burned samples).

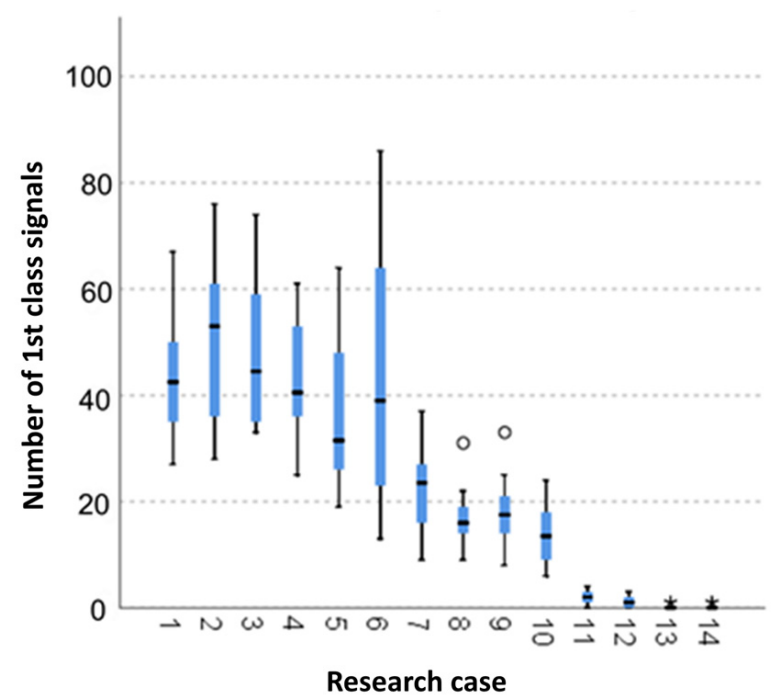

Figure 16. The graphical representation of the Kruskal-Wallis test results for independent samples of the number of class 1 signals. 
3.2.2. Kruskal-Wallis Test Results for Independent Samples of the Average Signal Strength of the Class 1 Signals

Analysing the graphical representation of the Kruskal-Wallis test results for independent tests of the average signal strength class 1 signals (Figure 17), it can be observed that the maximum mean power of the signals of this class was recorded for panels from the $\mathrm{A}_{4}$ test case (soaked-dried samples for 25 cycles). The largest scatter of results occurred for the $A_{7}$ group (frozen-thawed samples for 25 cycles). The lowest value of the average signal strength of class 1 signals was recorded for the $A_{12}$ test case (torched samples for $7.5 \mathrm{~min}$ ).

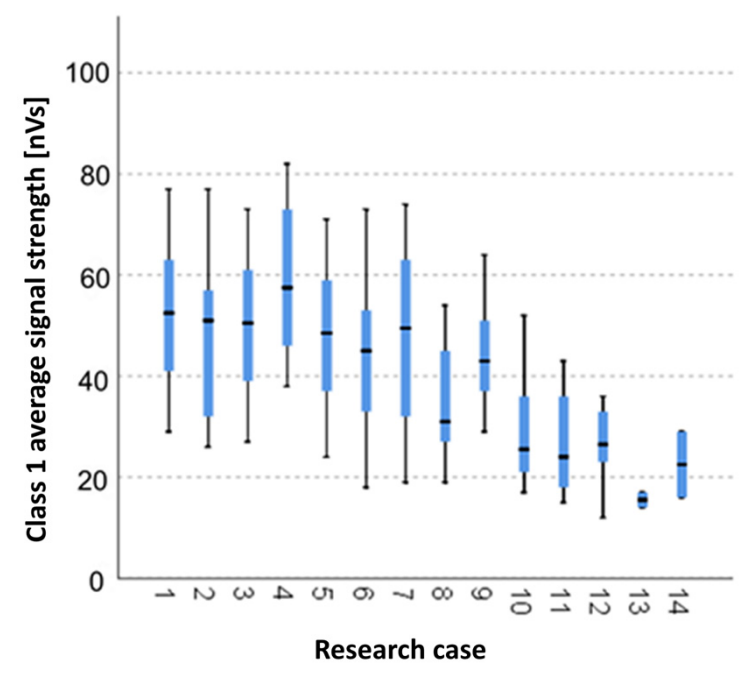

Figure 17. The graphical representation of the Kruskal-Wallis test results for independent samples of the average signal strength of the class 1 signals.

3.2.3. Kruskal-Wallis Test Results for Independent Tests of the Average Duration of the Class 1 Signals

Analysing the graphical representation of the Kruskal-Wallis test results for independent tests of the average duration of the class 1 signals (Figure 18), it can be observed that the average duration of the signals of this class was recorded for panels from the $A_{2}$ test case (soaked samples for $1 \mathrm{~h}$ ). Also for this case there was the largest scatter of results. The $A_{5}$ test case (soaked-dried samples for 50 cycles) contains a single statistical outlier. The lowest value of the duration of the class 1 signals was recorded for the $A_{11}$ test case (torched samples for $5 \mathrm{~min}$ ).

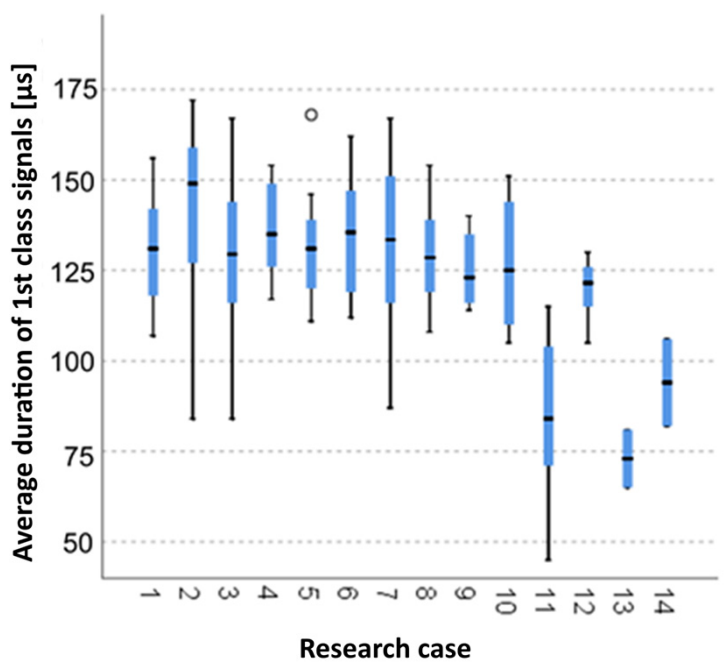

Figure 18. The graphical representation of the Kruskal-Wallis test results for independent tests of the average duration of the class 1 signals. 
3.2.4. Kruskal-Wallis Test Results for Independent Tests of the Number of Class 2 Signals

Analysing the graphical representation of the Kruskal-Wallis test results for independent tests of the number of class 2 signals (Figure 19), it can be observed that the maximum number of signals of this class was recorded for panels from the $A_{2}$ test case (soaked samples for $1 \mathrm{~h}$ ). Also for this case there was the largest scatter of results. The $\mathrm{A}_{10}$ test case (torched samples for $2.5 \mathrm{~min}$ ) contains a single statistical outlier. The lowest values for the number of class 2 signals were recorded for the $\mathrm{A}_{14}$ case (burnt samples).

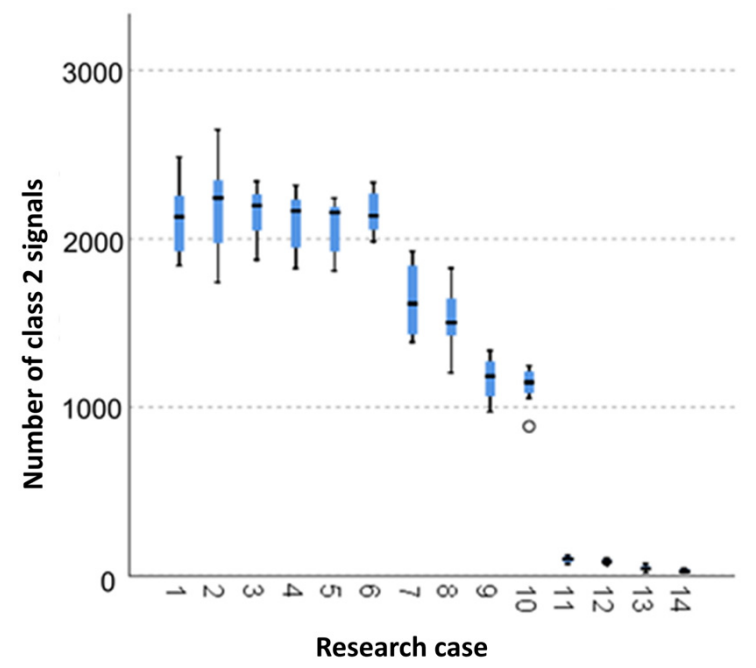

Figure 19. The graphical representation of the Kruskal-Wallis test results for independent tests of the number of class 2 signals.

3.2.5. Kruskal-Wallis Test Results for Independent Samples of the Average Signal Strength of the Class 2 Signals

Analysing the graphical representation of the Kruskal-Wallis test results for independent tests of the average signal strength of the class 2 signals (Figure 20), it can be observed that the maximum average signal strength of the signals of this class was recorded for panels from the $\mathrm{A}_{1}$ test case (air-dry samples). For this case there was also the largest scatter of results. The $\mathrm{A}_{4}$ test case (soaked-dried samples for 25 cycles) contains a single statistical outlier. The lowest value of the average signal strength of the class 2 signals was recorded for the $\mathrm{A}_{13}$ test case (torched samples for $10 \mathrm{~min}$ ).

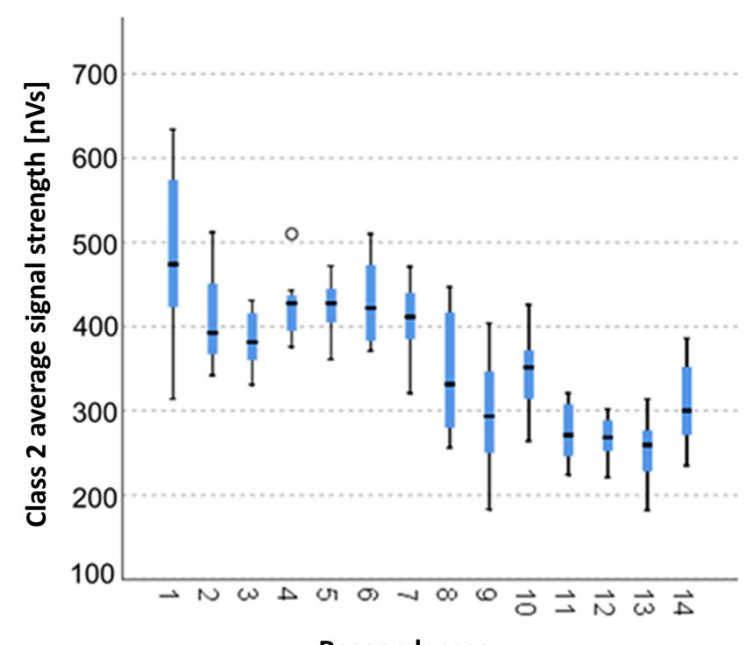

Research case

Figure 20. The graphical representation of the Kruskal-Wallis test results for independent samples of the average signal strength of the class 2 signals. 
3.2.6. Kruskal-Wallis Test Results for Independent Tests of the Average Duration of the Class 2 Signals

Analysing the graphical representation of the Kruskal-Wallis test results for independent tests of the average duration of the class 2 signals (Figure 21), it can be observed that the maximum average duration of the signals of this class was recorded for panels from the $A_{1}$ test case (air-dry samples). The largest scatter of results occurred for the $A_{3}$ group (soaked samples for $24 \mathrm{~h}$ ). The $\mathrm{A}_{12}$ test case (torched samples for $10 \mathrm{~min}$ ) contains a single statistical outlier. The lowest value of the average duration of the class 2 signals was recorded for the $\mathrm{A}_{13}$ test case (torched samples for $10 \mathrm{~min}$ ).

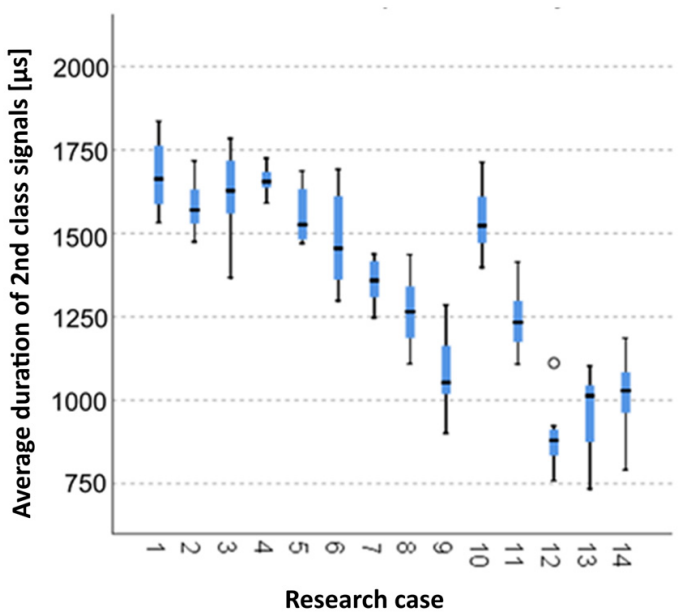

Figure 21. The graphical representation of the Kruskal-Wallis test results for independent tests of the average duration of the class 2 signals.

3.2.7. Kruskal-Wallis Test Results for Independent Tests of the Number of the Class 3 Signals

Analysing the graphical representation of the Kruskal-Wallis test results for independent tests of the number of class 3 signals (Figure 22), it can be observed that the maximum number of signals of this class was recorded for panels from the $A_{2}$ test case (soaked samples for $1 \mathrm{~h}$ ). The largest scatter of results occurred for the $A_{7}$ group (frozen-thawed samples for 25 cycles). The $A_{2}$ test case (samples soaked in water for $1 \mathrm{~h}$ ), $A_{5}$ (samples exposed to soaking-drying for 50 cycles) and $\mathrm{A}_{12}$ (torched samples for $7.5 \mathrm{~min}$ ) contain single statistical outliers. The lowest value of the number of the class 3 signals was recorded for the $\mathrm{A}_{13}$ test case (torched samples for $10 \mathrm{~min}$ ).

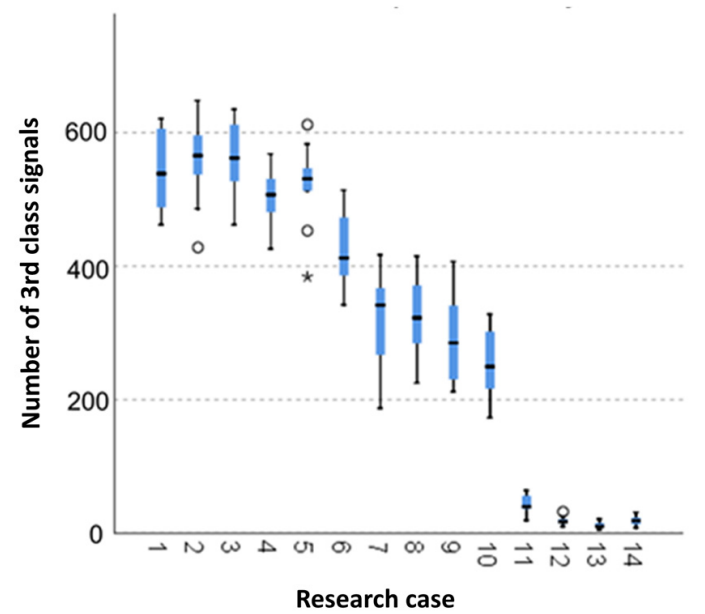

Figure 22. The graphical representation of the Kruskal-Wallis test results for independent tests of the number of the class 3 signals. 
3.2.8. Kruskal-Wallis Test Results for Independent Samples of the Average Signal Strength of the Class 3 Signals

Analysing the graphical representation of the Kruskal-Wallis test results for independent tests of the average signal strength of the class 3 signals (Figure 23), it can be observed that the maximum average signal strength of the signals of this class was recorded for panels from the $\mathrm{A}_{4}$ test case (soaked-dried samples for 25 cycles). The largest scatter of results occurred for the $\mathrm{A}_{8}$ group (frozen-thawed samples for 50 cycles). The $\mathrm{A}_{14}$ test case (burned samples) contains a single statistical outlier. The lowest values of the average signal strength of the class 3 signals was recorded for the $A_{13}$ test case (torched samples for $10 \mathrm{~min}$ ).

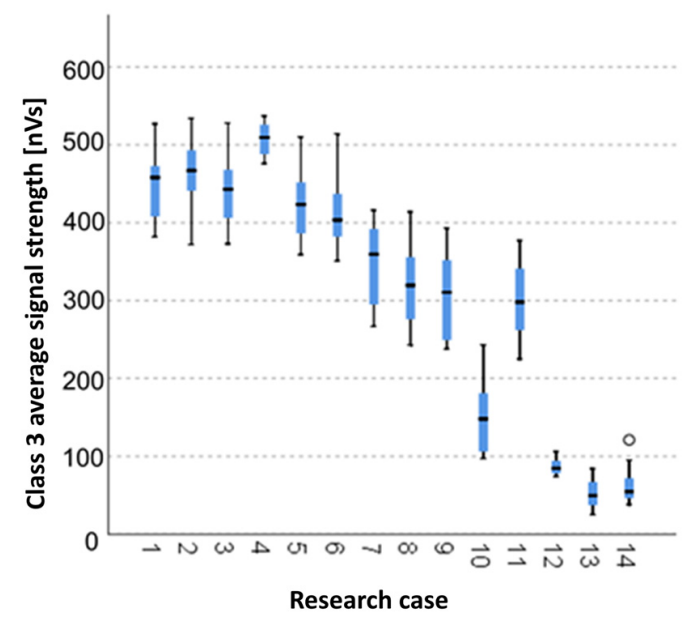

Figure 23. The graphical representation of the Kruskal-Wallis test results for independent samples of the average signal strength of the class 3 signals.

3.2.9. Kruskal-Wallis Test Results for Independent Tests of the Aver-Age Duration of the Class 3 Signals

Analysing the graphical representation of the Kruskal-Wallis test results for independent tests of the average duration of the class 3 signals (Figure 24), it can be observed that the maximum average duration of the signals of this class was recorded for panels from the $\mathrm{A}_{4}$ test case (soaked-dried samples for 25 cycles). The largest scatter of results occurred for the $A_{8}$ group (frozen-thawed samples for 50 cycles). The $A_{1}$ test case (air-dry samples) and $A_{14}$ (burned samples) contain single statistical outliers. The lowest value of the average duration of the class 3 signals was recorded for the $\mathrm{A}_{13}$ test case (torched samples for $10 \mathrm{~min}$ ).

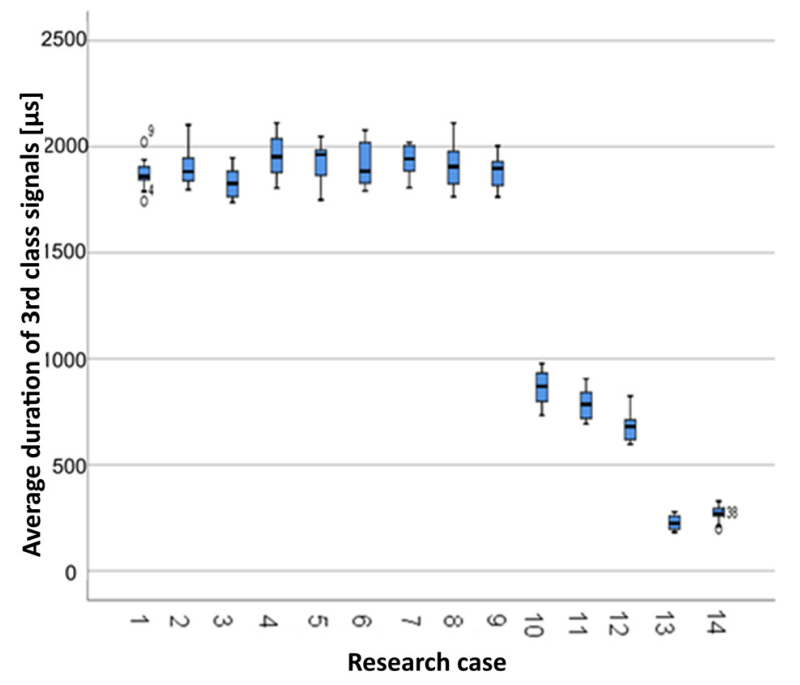

Figure 24. The graphical representation of the Kruskal-Wallis test results for independent tests of the average duration of the class 3 signals. 
3.2.10. Kruskal-Wallis Test Results for Independent Tests of the Number of the Class 4 Signals

Analysing the graphical representation of the Kruskal-Wallis test results for independent tests of the number of class 4 signals (Figure 25), it can be observed that the maximum number of signals of this class was recorded for panels from the $A_{2}$ test case (soaked samples for $1 \mathrm{~h}$ ). The largest scatter of results occurred for the $\mathrm{A}_{6}$ group (frozen-thawed samples for 10 cycles). The $A_{4}$ test case (soaked-dried samples for 50 cycles) contains single statistical outliers. The lowest values for the number of the class 4 signals were recorded for the $\mathrm{A}_{14}$ case (burnt samples).

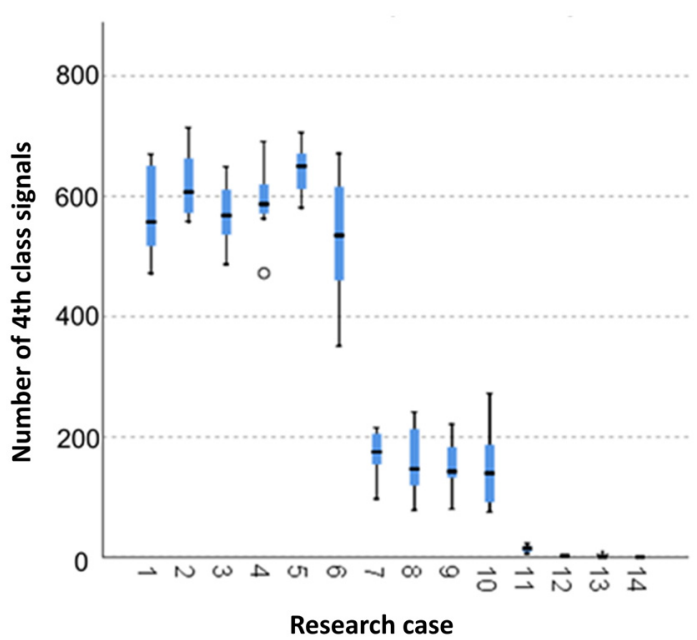

Figure 25. The graphical representation of the Kruskal-Wallis test results for independent tests of the number of the class 4 signals.

3.2.11. Kruskal-Wallis Test Results for Independent Samples of the Average Signal Strength of the Class 4 Signals

Analysing the graphical representation of the Kruskal-Wallis test results for independent tests of the average signal strength of class 4 signals (Figure 26), it can be observed that the maximum average signal strength of the signals of this class was recorded for panels from the $\mathrm{A}_{2}$ test case (soaked samples for $1 \mathrm{~h}$ ). The largest scatter of results occurred for the $A_{6}$ group (frozen-thawed samples for 10 cycles). The $A_{2}$ test case (soaked samples for $1 \mathrm{~h}$ ) contains single statistical outliers. The lowest values for the average signal strength of the class 4 signals were recorded for the $\mathrm{A}_{14}$ case (burnt samples).

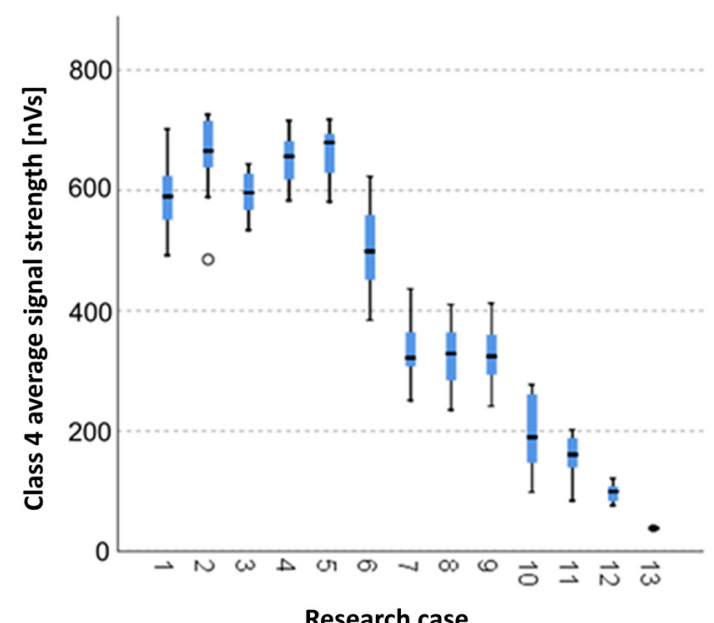

Figure 26. The graphical representation of the Kruskal-Wallis test results for independent samples of the average signal strength of the class 4 signals. 
3.2.12. Kruskal-Wallis Test Results for Independent Tests of the Average Duration of the Class 4 Signals

Analysing the graphical representation of the Kruskal-Wallis test results for independent tests of the average duration class 4 signals (Figure 27), it can be observed that the average duration of the signals of this class was recorded for panels from the $\mathrm{A}_{2}$ test case (soaked samples for $1 \mathrm{~h}$ ). The largest scatter of results occurred for the $\mathrm{A}_{5}$ case (soaked-dried samples for 50 cycles). The $A_{3}$ test case (samples soaked in water for $24 \mathrm{~h}$ ), $\mathrm{A}_{6}$ (frozen-thawed samples for 10 cycles) and $A_{7}$ (frozen-thawed samples for 25 cycles) contain single statistical outliers. The lowest values for the average duration of the class 4 signals were recorded for the $\mathrm{A}_{14}$ case (burnt samples).

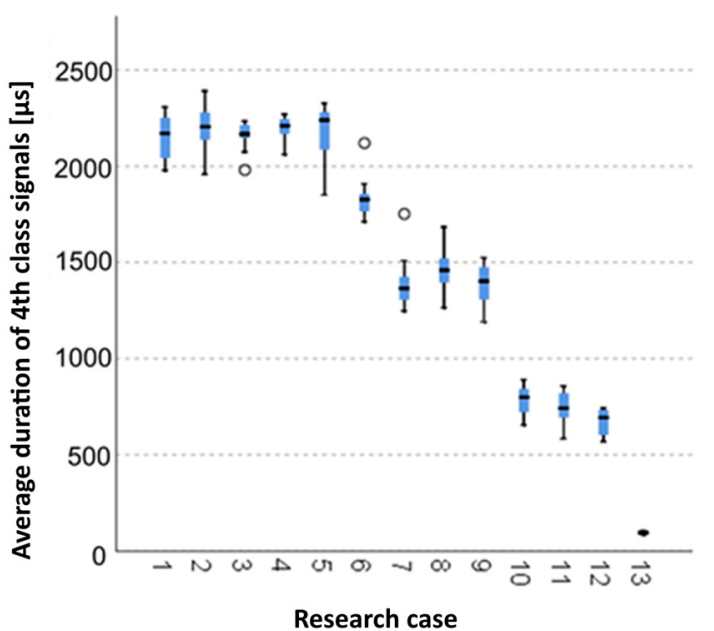

Figure 27. The graphical representation of the Kruskal-Wallis test results for independent tests of the average duration of the class 4 signals.

\subsubsection{Kruskal-Wallis Test Results for Independent Tests of the $F_{\text {max }}$ Break Force}

Analysing the graphical representation of the Kruskal-Wallis test results for independent tests of the $F_{\text {max }}$ break force (Figure 28), it can be observed that the maximum destructive force was recorded for panels from the $A_{5}$ test case (soaked-dried samples for 50 cycles). For this case there was also the largest scatter of results. The $A_{11}$ test case (burned samples for $50 \mathrm{~min}$.) and $\mathrm{A}_{12}$ (torched samples for $7.5 \mathrm{~min}$.) contain single statistical outliers. The lowest value of the $F_{\text {max }}$ break force was recorded for the $\mathrm{A}_{13}$ test case (torched samples for $10 \mathrm{~min}$ ).

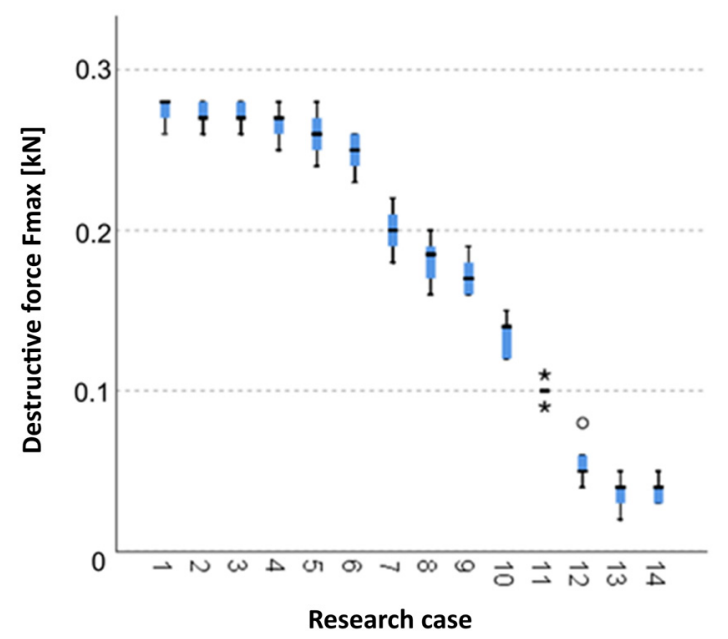

Figure 28. Kruskal-Wallis test results for independent tests of the $F_{\max }$ break force. 


\subsubsection{Checking the Significance of the Correlation}

The Shapiro-Wilk test was conducted to examine the normality of the data distribution. In most cases the data do not have a normal distribution. Therefore, the Spearman correlation coefficient (a non-parametric measure of monotonic statistical dependence between random variables) was used to examine the relationship between the indicated variations. A significant correlation was found to exist between:

- The number of the class 1 signals and the destructive force $F_{\max }(\rho=0.809, \mathrm{p}=0.000)$. The more signals, the higher the destructive force.

- The average signal strength of the class 1 signals and the destructive force $F_{\max }$ $(\rho=0.374, p=0.000)$. The greater power of the signals, the higher the destructive force.

- The number of class 2 signals and the destructive force $F_{\max }(\rho=0.718, \mathrm{p}=0.000)$. The more signals, the higher the destructive force.

- The average signal strength of the class 2 signals and the destructive force $F_{\max }$ $(\rho=0.633, p=0.000)$. The greater power of the signals, the higher the destructive force.

- The average duration of the class 2 signals and the destructive force $F_{\max }(\rho=0.737$, $p=0.000)$. The greater average duration of the signals, the higher the destructive force.

- The number of the class 3 signals and the destructive force $F_{\max }(\rho=0.667, \mathrm{p}=0.000)$. The more signals, the higher the destructive force.

- The average signal strength of the class 3 signals and the destructive force $F_{\max }$ $(\rho=0.480, p=0.000)$. The greater power of the signals, the higher the destructive force.

- The average duration of the class 3 signals and the destructive force $F_{\max }(\rho=0.493$, $\mathrm{p}=0.000$ ). The greater average duration of the signals, the greater the destructive force.

- The number of the class 4 signals and the destructive force $F_{\max }(\rho=0.780, \mathrm{p}=0.000)$. The more signals, the higher the destructive force.

- The average signal strength of the class 4 signals and the destructive force $F_{\max }$ $(\rho=0.735, p=0.000)$. The greater power of the signals, the higher the destructive force.

- The average duration of the class 4 signals and the destructive force $F_{\max }(\rho=0.766$, $p=0.000)$. The greater average duration of the signals, the higher the destructive force.

Based on the distribution of the results of Kruskal-Wallis tests for individual parameters and taking into account the significance of the correlation between them, it can be concluded that the differences in the number of recorded acoustic emission signals of particular classes and the parameters of these signals make it possible to create groups characterizing AE events in connection with the mechanical parameters of boards. This is what has been treated as the basis of the methodology for assessing the condition of cement-cellulose boards.

\section{Discussion}

Given the results of the tests and the resulting conclusions indicating the applicability of the acoustic emission method based on signal classification using the k-means algorithm for the assessment of variations in the mechanical parameters of cement-fibre composites, a methodology for such assessment was therefore developed. The approach proposed is a reasonable method for assessing the variation in mechanical parameters of fibrecement panels on the basis of the parameters determined by the non-destructive method indicated. During the development of the methodology, the results of research of the recorded frequencies of events were also used, and an approach to tracking acoustic spectra of signals was included, which, according to the authors, is useful as a refinement of observations.

The suggested methodology is shown schematically on Figure 29. Three stages can be distinguished in this scheme. Stage 1 involves plotting a grid of measurement points on the façade covered with fibre-cement panels at a spacing not exceeding $10 \mathrm{~m}$. The measuring points along the edge of the panel should be located approximately $50 \mathrm{~mm}$ from it. The next step is to prepare the acoustic emission measurement, including sensor testing and elimination of background noise. The next step is to take a measurement. Next, it is necessary to perform a linear localization that allows the precise location of the points 
where AE signals are produced. Based on these steps, it is possible to identify potential panels where mechanical deterioration may have occurred.

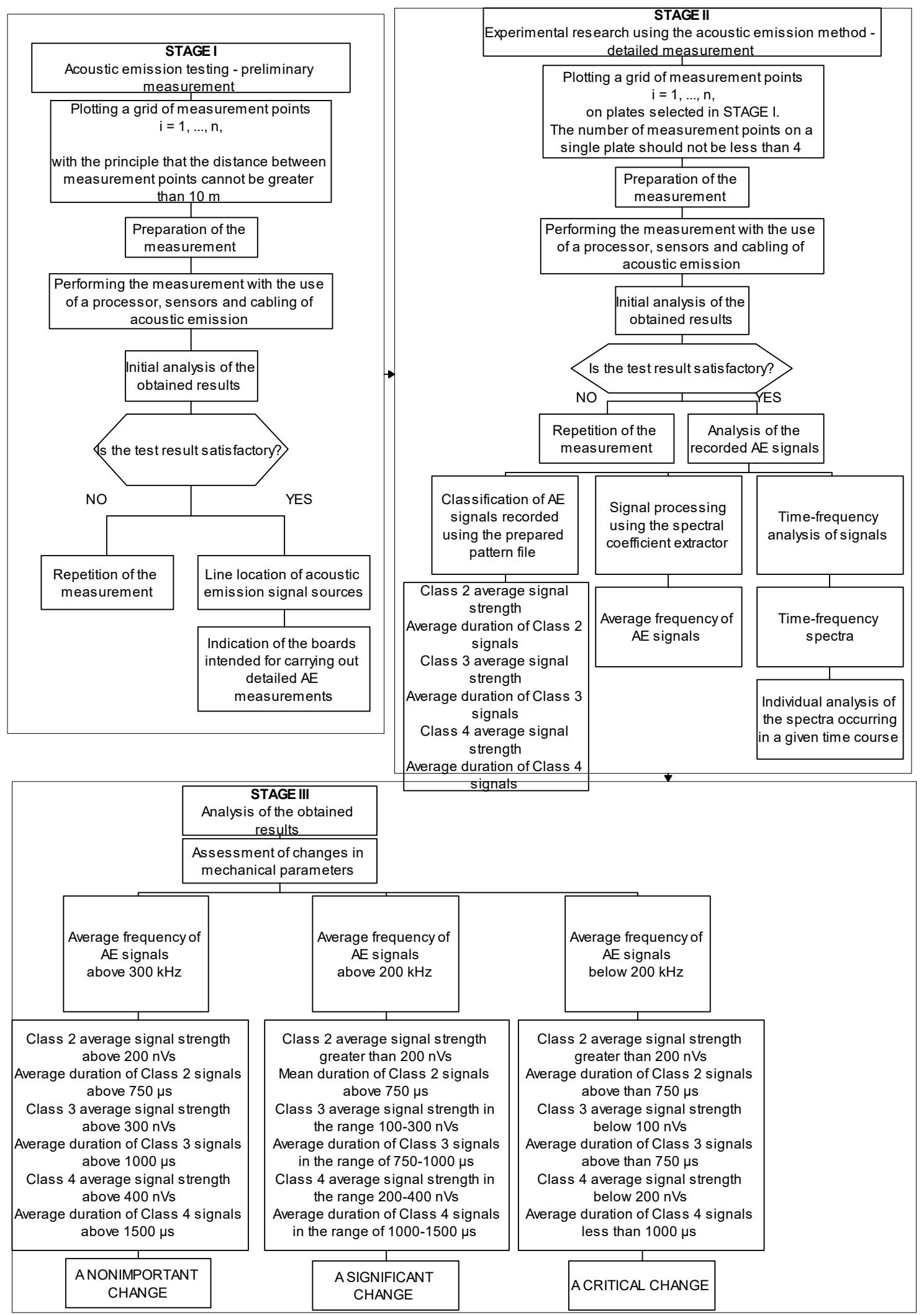

Figure 29. Diagram illustrating the methodology of assessing the change of mechanical parameters of fiber-cement boards under the influence of operational factors. 
Stage 2 involves conducting acoustic emission measurements on the panels selected in stage 1. Taking into account the size of a single fibre-cement panel used as a façade cladding, it is recommended that the number of measurement points on a single panel should be not less than 4. Again, the distance between the AE sensor locations and the edge of the panel must be at least $50 \mathrm{~mm}$. Once the measurement has been prepared, proceed to the recording of the AE signals. Due to the operating nature of the cladding, it is recommended that the signal acquisition is performed at increased strain on the individual components (preferably during relatively strong wind pressure). Once the measurement is complete, the recorded signals must be processed. The first stage of the analysis involves the classification of AE signals using the developed reference file. At this stage of processing, it is important to remember that signals with a coefficient of determination R2 (matching a given class) of at least $90 \%$ can be adopted to assess the extent of variation in mechanical parameters. In the next step, the values of the average signal strength and duration of the class 2,3 , and 4 signals have to be analysed.

The final stage (3) is an analysis of the previously obtained results using this testing method with three approaches to process the recorded signals. The analysis is aimed at determining and assessing the extent to which the mechanical parameters change when exposed to the service conditions of the fibre-cement panels tested, based on the results of the conducted tests. Insignificant change in mechanical performance means average signal strength of the class 2 signals over $200 \mathrm{nVs}$, average duration of the class 2 signals over $750 \mu \mathrm{s}$, average signal strength of the class 3 signals over $300 \mathrm{nVs}$, average duration of the class 3 signals over $150 \mu \mathrm{s}$, average signal strength of the class 4 signals over $400 \mathrm{nVs}$, average duration of the class 4 signals over $1500 \mu$ s, and average frequency of AE signals over $300 \mathrm{kHz}$. Significant change in mechanical performance means average signal strength of the class 2 signals over $200 \mathrm{nVs}$, average duration of the class 2 signals over $750 \mu \mathrm{s}$, average signal strength of the class 3 signals within $100-300 \mathrm{nVs}$, average duration of the class 3 signals within 100-150 $\mu \mathrm{s}$, average signal strength of the class 4 signals within $200-400 \mathrm{nVs}$, average duration of the class 4 signals within 1000-1500 $\mu$ s, and average frequency of AE signals within $200-300 \mathrm{kHz}$. Critical change in mechanical performance means average signal strength of the class 2 signals over $200 \mathrm{nVs}$, average duration of the class 2 signals over $750 \mu \mathrm{s}$, average signal strength of the class 3 signals over $100 \mathrm{nVs}$, average duration of the class 3 signals below $100 \mu \mathrm{s}$, average signal strength of the class 4 signals below $200 \mathrm{nVs}$, average duration of the class 4 signals below $1000 \mu \mathrm{s}$, and average frequency of AE signals below $300 \mathrm{kHz}$.

The insignificant change in mechanical parameters is associated with a reduction in MOR flexural strength of no more than $30 \%$ with respect to the reference panels. The significant change is a reduction in strength by more than $30 \%$ but less than $50 \%$. Deterioration of strength properties by more than $50 \%$ was classified as a critical change in mechanical performance.

The advantages of the presented methodology relate primarily to the general advantages of using the phenomenon of acoustic emission:

- The ability to detect a range of failure mechanisms related to the processes that characterize particular classes of signals in the early stages before they become significant problems;

- The possibility of observation during the operation of the boards;

- The ability to locate the sources of damage and to distinguish them;

- The ability to perform global monitoring of the building object;

- The possibility of assessing the structure in real operating conditions;

- Non-invasive method;

- Possibility of remote monitoring;

- The ability to detect hard-to-reach damage.

The methodology limits are as follows:

- No possibility to detect existing damage that does not develop and propagate; 
- Extended monitoring time compared to other non-destructive methods (e.g., ultrasonic method).

\section{Conclusions}

When applying the acoustic emission method, two main approaches are used to analyse the acoustic data: the study of AE signal descriptors and/or waveform analysis. In both approaches, data processing is usually based on the analysis of single descriptors or groups of descriptors. However, given the fact that the process of degradation of a building component or structure is not a deterministic but a random process, such a solution causes problems with identification of physical phenomena causing destructive processes. Therefore, current procedures based on precise load control make it difficult to perform diagnostics on large building components under field conditions. Rather, the methods and procedures currently in use are expected to provide information that allows conclusions to be drawn about the effect of recorded defects on the load-bearing capacity and durability of the panels with cement matrix.

Under the conditions in which cement-fibre cladding panels operate, assessment on the basis of the current criteria based on single parameters of acoustic signals is unlikely to solve the problem, making it necessary to develop a new concept for assessing the extent of destruction of a civil engineering structure.

The methodology presented in this paper is a preliminary version of a reliable assessment of changes in the mechanical parameters of the fibre-cement panels. It is the intention of the authors that, once refined, it will enable panel diagnostics to be performed without the need for any expert training in this area.

Author Contributions: Conceptualization, A.A.-B. and A.K.; methodology, G.Ś.; software, G.Ś.; validation, G.Ś., A.A.-B., and A.K.; formal analysis, A.A.-B.; investigation, A.A.-B.; resources, G.Ś.; data curation, A.A.-B.; writing-original draft preparation, A.A.-B.; writing-review and editing, A.K.; visualization, G.Ś.; supervision, G.Ś. All authors have read and agreed to the published version of the manuscript.

Funding: This research received no external funding.

Institutional Review Board Statement: Not applicable.

Informed Consent Statement: Not applicable.

Data Availability Statement: Not applicable.

Conflicts of Interest: The authors declare no conflict of interest.

\section{References}

1. Ardanuy, M.; Claramunt, J.; Toledo Filho, R.D. Cellulosic Fibre Reinforced Cement-Based Composites: A Review of Recent Research. Constr. Build. Mater. 2015, 79, 115-128. [CrossRef]

2. Faruk, O.; Bledzki, A.K.; Fink, H.P.; Sain, M. Biocomposites reinforced with natural fibers. Prog. Polym. Sci. 2012, 37, 1552-1596. [CrossRef]

3. Tonoli, G.H.D.; Santos, S.F.; Savastano, H.; Delvasto, S.; Mejía de Gutiérrez, R.; Lopez de Murphy, M.D.M. Effects of natural weathering on microstructure and mineral composition of cementitious roofing tiles reinforced with fique fibre. Cem. Concr. Compos. 2011, 33, 225-232. [CrossRef]

4. Morton, J.H.; Cooke, T.; Akers, S.S. Performance of slash pine fibers in fiber cement products. Constr. Build. Mater. 2010, 24, 165-170. [CrossRef]

5. Khorami, M.; Ganjian, E. The effect of limestone powder, silica fume and fibre content on flexural behaviour of cement composite reinforced by waste Kraft pulp. Constr. Build. Mater. 2013, 46, 142-149. [CrossRef]

6. Claramunt, J.; Ardanuy, M.; Parés, F.; Ventura, H. Mechanical performance of cement mortar composites reinforced with cellulose fibres. In Proceedings of the 9th International conference on Composite Science and Technology, Sorrento, Italy, 24-26 April 2013; DESTech Publications: Lancaster, PA, USA, 2013; pp. 477-484.

7. Claramunt, J.; Ventura, H.; Parés, F.; Ardanuy, M. Natural fibre nonwovens as reinforcement for cement mortar composites. In Proceedings of the 1st International Conference on Natural Fibers-Sustainable Materials for Advanced Applications, Universidade do Minho, Guimarães, Portugal, 9-11 June 2013; pp. 191-192. 
8. Claramunt, J.; Ardanuy, M.; García-Hortal, J.A.; Filho, R.D.T. The hornification of vegetable fibers to improve the durability of cement mortar composites. Cem. Concr. Compos. 2011, 33, 586-595. [CrossRef]

9. Ferreira, S.R. Influence of Hornification on Fiber-Matrix Adhesion and Mechanical Behavior of Cementitious Composites Reinforced with Short Sisal Fibers; Universidade Federal de Feira de Santana: Feira de Santana, Brazil, 2012.

10. Melo Filho, J.D.A.; Silva, F.D.A.; Toledo Filho, R.D. Degradation kinetics and aging mechanisms on sisal fiber cement composite systems. Cem. Concr. Compos. 2013, 40, 30-39. [CrossRef]

11. Mohr, B.J.; Biernacki, J.J.; Kurtis, K.E. Microstructural and chemical effects of wet/dry cycling on pulp fiber-cement composites. Cem. Concr. Res. 2006, 36, 1240-1251. [CrossRef]

12. Claramunt, J.; Ardanuy, M.; García-Hortal, J.A. Effect of drying and rewetting cycles on the structure and physicochemical characteristics of softwood fibres for reinforcement of cementitious composites. Carbohydr. Polym. 2010, 79, 200-205. [CrossRef]

13. Mohr, B.J.; Nanko, H.; Kurtis, K.E. Durability of kraft pulp fibre-cement composites to wet/dry cycling. Cem. Concr. Compos. 2005, 27, 435-448. [CrossRef]

14. Adamczak-Bugno, A.; Świt, G.; Krampikowska, A. Application of the Acoustic Emission Method in the Assessment of the Technical Condition of Steel Structures. In IOP Conference Series: Materials Science and Engineering; IOP Publishing: Bristol, UK, 2019; Volume 471, p. 032041.

15. Pizzol, V.D.; Mendes, L.M.; Savastano, H.; Frías, M.; Davila, F.J.; Cincotto, M.A.; John, V.M.; Tonoli, G.H.D. Mineralogical and microstructural changes promoted by accelerated carbonation and ageing cycles of hybrid fibre-cement composites. Constr. Build. Mater. 2014, 68, 750-756. [CrossRef]

16. Adamczak-Bugno, A.; Świt, G.; Krampikowska, A. Assessment of Destruction Processes in Fibre-Cement Composites Using the Acoustic Emission Method and Wavelet Analysis. In IOP Conference Series: Materials Science and Engineering; IOP Publishing: Bristol, UK, 2019; Volume 471, p. 032042.

17. Tonoli, G.H.D.; Santos, S.F.; Joaquim, P.; Savastano, H. Effect of accelerated carbonation on cementitious roofing tiles reinforced with lignocellulosic fibre. Constr. Build. Mater. 2010, 24, 193-201. [CrossRef]

18. Bentchikou, M.; Guidoum, A.; Scrivener, K.; Silhadi, K.; Hanini, S. Effect of recycled cellulose fibres on the properties of lightweight cement composite matrix. Constr. Build. Mater. 2012, 34, 451-456. [CrossRef]

19. Schabowicz, K. Aging of ventilated facades made of fiber-cement panels. Insulations 2020, 25, 72-74. (In Polish)

20. Schabowicz, K.; Sulik, P.; Zawiślak, Ł. Reduction of load capacity of fiber cement board facade cladding under the influence of fire. Materials 2021, 14, 1769. [CrossRef] [PubMed]

21. Świt, G.; Adamczak, A.; Krampikowska, A. Wavelet Analysis of Acoustic Emissions during Tensile Test of Carbon Fibre Reinforced Polymer Composites. In IOP Conference Series: Materials Science and Engineering; IOP Publishing: Bristol, UK, 2017; Volume 245, p. 022031.

22. Li, Z.; Zhou, X.; Bin, S. Fibre-Cement extrudates with perlite subjected to high temperatures. J. Mater. Civ. Eng. 2004, 3, 221-229. [CrossRef]

23. Świt, G.; Adamczak, A.; Krampikowska, A. Time-frequency analysis of acoustic emission signals generated by the Glass Fibre Reinforced Polymer Composites during the tensile test. In IOP Conference Series: Materials Science and Engineering; IOP Publishing: Bristol, UK, 2017; Volume 251, p. 012002.

24. Świt, G.; Krampikowska, A. Influence of the number of acoustic emission descriptors on the accuracy of destructive process identification in concrete structures. In Proceedings of the 2016 Prognostics and System Health Management Conference, PHM-Chengdu, Chengdu, China, 19-21 October 2016.

25. Chinh, L.M.; Adamczak, A.; Krampikowska, A.; Swit, G. Dragon bridge-The world largest dragon-shaped (ARCH) steel bridge as element of smart city. E3S Web Conf. 2016, 10, 1-16. [CrossRef]

26. Schabowicz, K.; Józwiak-Niedzwiedzka, D.; Ranachowski, Z.; Kudela, S.; Dvorak, T. Microstructural characterization of cellulose fibres in reinforced cement boards. Arch. Civ. Mech. Eng. 2018, 4, 1068-1078. [CrossRef]

27. Świt, G.; Krampikowska, A.; Chinh, L.M.; Adamczak, A. Nhat Tan Bridge-The Biggest Cable-Stayed Bridge in Vietnam. Procedia Eng. 2016, 161, 666-673. [CrossRef]

28. Stark, W. Non-destructive evaluation (NDE) of composites: Using ultrasound to monitor the curing of composites. In Nondestructive Evaluation (NDE) of Polymer Matrix Composites. Techniques and Applications, 1st ed.; Karbhari, V.M., Ed.; Woodhead Publishing Limited: Cambridge, UK, 2013; pp. 136-181.

29. Debowski, T.; Lewandowski, M.; Mackiewicz, S.; Ranachowski, Z.; Schabowicz, K. Ultrasonic tests of fibre-cement boards. Weld. Rev. 2016, 10, 69-71. (In Polish)

30. Drelich, R.; Gorzelanczyk, T.; Pakuła, M.; Schabowicz, K. Automated control of cellulose fibre cement boards with a non-contact ultrasound scanner. Autom. Constr. 2015, 57, 55-63. [CrossRef]

31. Ranachowski, Z.; Schabowicz, K. The contribution of fibre reinforcement system to the overall toughness of cellulose fibre concrete panels. Constr. Build. Mater. 2017, 156, 1028-1034. [CrossRef]

32. Schabowicz, K.; Gorzelanczyk, T.; Szymków, M. Identification of the degree of degradation of fibre-cement boards exposed to fire by means of the acoustic emission method and artificial neural networks. Materials 2019, 12, 656. [CrossRef] 
33. Goszczyńska, B.; Świt, G.; Trąmpczyński, W.; Krampikowska, A. Application of the acoustic emission method of identification and location of destructive processes to the monitoring concrete bridges. In Bridge Maintenance, Safety, Management and Life Extension, Proceedings of the 7th International Conference of Bridge Maintenance, Safety and Management, IABMAS 2014, Shanghai, China, 7-11 July 2014; CRC Press: London, UK, 2014; pp. 688-694.

34. Lim, M.K.; Cao, H. Combining multiple NDT methods to improve testing effectiveness. Constr. Build. Mater. 2013, 38, 1310-1615. [CrossRef] 